\title{
Effect of Fe ion concentration on fatigue life of carbon steel in aqueous $\mathrm{CO} 2$ environment
}

\author{
Rogowska, Magdalena; Gudme, J.; Rubin, A.; Pantleon, Karen; Ambat, Rajan
}

Published in:

Corrosion Engineering Science and Technology

Link to article, DOI:

10.1179/1743278215Y.0000000035

Publication date:

2016

Document Version

Peer reviewed version

Link back to DTU Orbit

\section{Citation (APA):}

Rogowska, M., Gudme, J., Rubin, A., Pantleon, K., \& Ambat, R. (2016). Effect of Fe ion concentration on fatigue life of carbon steel in aqueous CO2 environment. Corrosion Engineering Science and Technology, 51(2), 90103. https://doi.org/10.1179/1743278215Y.0000000035

\section{General rights}

Copyright and moral rights for the publications made accessible in the public portal are retained by the authors and/or other copyright owners and it is a condition of accessing publications that users recognise and abide by the legal requirements associated with these rights.

- Users may download and print one copy of any publication from the public portal for the purpose of private study or research.

- You may not further distribute the material or use it for any profit-making activity or commercial gain

- You may freely distribute the URL identifying the publication in the public portal 
The effect of Fe ion concentration on the fatigue life of carbon steel in an aqueous $\mathrm{CO}_{2}$ environment

$$
\begin{gathered}
\text { Magdalena Rogowska }^{\mathrm{a}, \mathrm{b}, *} \text {, Jonas Gudme } \\
\text { Rajan Ambat }{ }^{\mathrm{b}}
\end{gathered}
$$

${ }^{a}$ National Oilwell Varco Denmark I/S, Material Technology, Priorparken 480, DK-2605 Brøndby, Denmark

${ }^{\mathrm{b}}$ Technical University of Denmark, Department of Mechanical Engineering, Produktionstorvet, Building 425, DK - 2800 Kongens Lyngby, Denmark

*Corresponding author: Tel.: +45 41908465

E-mail address: Magdalena.Rogowska@nov.com

\section{ABSTRACT}

In this work, the corrosion fatigue behavior of steel armours used in the flexible pipes, in aqueous solutions initially containing different concentrations of $\mathrm{Fe}^{2+}$, was investigated by four point bending testing under saturated 1 bar $\mathrm{CO}_{2}$ condition. Corrosion fatigue results were supported with ex-situ measurements of $\mathrm{Fe}^{2+}$ and $\mathrm{pH}$. Characterization of the corrosion scales and crack formations was performed using microscopic and diffraction techniques. Fatigue results showed two times better fatigue life, at the stress ranges of $250 \mathrm{MPa}$, for samples tested in solutions containing the

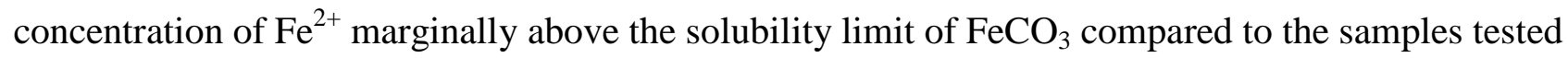
in highly supersaturated solution of $\mathrm{Fe}^{2+}$. Results revealed that the impact of the alternating stresses on the corrosion behavior of samples reduces with lowering the applied stresses. At the stress range of $100 \mathrm{MPa}$ fatigue samples experienced the same corrosion rate as samples which were not subjected to dynamic loading.

Keywords: Carbon steel, Carbon Dioxide, Corrosion fatigue, Supersaturation, Iron carbonate

\section{Introduction}

Flexible pipes, which are used in the oil and gas industry, are an attractive alternative to rigid pipes, due to their shorter installation times and longer durability. The typical structure of flexible pipes is 
composed of polymeric and steel layers, which are not bonded together, to ensure the flexibility of the pipe. ${ }^{1}$ The fatigue life of a flexible pipe is determined by the fatigue life of the steel armours, which is placed in the annular space between the inner liner and outer sheath. It was reported ${ }^{2}$ that the fatigue life of tensile armour depends on the applied stresses, which are generated due to waves and water current, and the corrosive operating environment. The annulus region might be water filled either due to diffusion and condensation of water from the bore or as a result of a breakage of the outer sheath allowing the entry of seawater. In addition, the severity of the corrosion environment may be increased due to diffusion of small molecules such as methane $\left(\mathrm{CH}_{4}\right)$, carbon dioxide $\left(\mathrm{CO}_{2}\right)$, and hydrogen sulphide $\left(\mathrm{H}_{2} \mathrm{~S}\right)$ from the pipe bore through the inner liner into the annulus. $^{1-3}$ However, due to a low ratio of free water volume (V) to steel surface area (S), typically below $0,1 \mathrm{ml} \mathrm{cm}^{-2}$ (Ref. 3), a rapid, high supersaturation of $\mathrm{Fe}^{2+}$ in the liquid is possible. As a consequence low corrosion rates, usually below $10 \mu \mathrm{m} /$ year are achieved. ${ }^{3,4}$

The corrosion behavior of steel in aqueous $\mathrm{CO}_{2}$ solution is influenced by the formation of protective films, which might decrease their corrosion rate. ${ }^{5,6}$ Typical corrosion scales, formed in such an environment, consist of iron carbonate (siderite, $\left.\mathrm{FeCO}_{3}\right)$ and undissolved cementite $\left(\mathrm{Fe}_{3} \mathrm{C}\right)^{7,8} \mathrm{~A}$ large number of environmental variables, such as $\mathrm{pH}^{9-11}$ temperature, ${ }^{9,12,13}$ partial pressure ${ }^{11}$ and flow rate ${ }^{14-17}$ influence the corrosion behavior of steel. Further, material characteristics such as microstructure, chemical composition, and heat treatment condition ${ }^{18-20}$ will also have a significant impact.

The concentration of $\mathrm{Fe}^{2+}$ in the solution is one of the main factors influencing the kinetics of scale formation. ${ }^{21,22}$ It was reported ${ }^{7,14,23,24}$ that the precipitation rate of $\mathrm{FeCO}_{3}$ at temperatures below $60^{\circ} \mathrm{C}$ is relatively slow due to high solubility of $\mathrm{FeCO}_{3}$. In order to form a protective $\mathrm{FeCO}_{3}$ scale, supersaturation of $\mathrm{Fe}^{2+}(\mathrm{SR}>1)$ is necessary, particularly at temperatures below $20^{\circ} \mathrm{C}$ (Ref.11). No 
passive films develop when the concentration of $\mathrm{Fe}^{2+}$ does not exceed the solubility limit of $\mathrm{FeCO}_{3}$ (Ref. 25).

Corrosion fatigue is defined as a sequential damage of material subjected to cyclic load in a corrosive environment ${ }^{26}$ and it accumulates in four stages: 1) cyclic plastic deformation, 2) microcrack initiation, 3) small crack growth including linkup and formation of crack networks, and 4) macro crack propagation. ${ }^{26,27}$ Rate of crack growth reported to increase significantly under corrosive conditions. ${ }^{28,29}$ This leads to significant reduction in fatigue life ${ }^{30}$ and the endurance limit, as under atmospheric conditions, might no longer be observed. ${ }^{26-28}$ On the other hand, corrosion products could also blunt the crack tips leading to crack retardation. ${ }^{31,32}$ Corrosion fatigue is a complex process and involves interactions between mechanical, metallurgical, chemical, and electrochemical variables. ${ }^{22,23,33}$ Many mechanisms are responsible for corrosion fatigue damage, such as hydrogen embrittlement, scale rupture, dissolution and repassivation, and enhanced localized plasticity. ${ }^{26,34,35}$ Pitting is one of the principal mechanisms for crack initiation in corrosive environments. $^{27,28,36}$

When exposing steels to aqueous $\mathrm{CO}_{2}$ solutions their fatigue life is reduced compared to air conditions. ${ }^{28,37,38}$ Experiments revealed ${ }^{37}$ that by exposing samples to corrosive $\mathrm{CO}_{2}$ environment, the time to failure is approximately 10 to 50 times shorter compared to the fatigue life in air conditions. The results showed ${ }^{37,39}$ that the fatigue life decreased as a function of $\mathrm{CO}_{2}$ partial pressure and the effect of $\mathrm{CO}_{2}$ content was more evident at lower stress ranges, such as $400 \mathrm{MPa}$ (Ref.37). Both $\mathrm{pH}$ and the composition of the electrolyte play an important factor in corrosion fatigue mechanisms. ${ }^{26,40,41}$ However, very little work has been published, on the influence of the initial $\mathrm{Fe}^{2+}$ content in $\mathrm{CO}_{2}$ environment, on the fatigue behavior of steel. Fatigue studies of the conditions found in flexible pipes have focused on developing test methods ${ }^{2}$ and methodologies used in fatigue analysis. ${ }^{42,43}$ Only few publications detail on the corrosion fatigue data in an aqueous 
$\mathrm{CO}_{2}$ environment. ${ }^{37-39,44-46}$ The publications are based on limited datasets, while detailed analysis of the impact of corrosion mechanisms on the fatigue performance is still not explored. This includes the effect of highly supersaturated solution of $\mathrm{Fe}^{2+}$, typically found in annulus conditions.

The objective of the present paper is to investigate the influence of the initial $\mathrm{Fe}^{2+}$ concentration and corresponding alkalinity of the solution $\left(\mathrm{HCO}_{3}{ }^{-}\right)$, together with resulting $\mathrm{pH}$ on the corrosion fatigue life of the steels used in flexible pipes. Experiments were performed under dynamic conditions by applying a four point bending test, while simultaneously exposing materials to the corrosive media. Tests were performed in seawater saturated at 1 bar $\mathrm{CO}_{2}$ under atmospheric pressure at room temperature. The obtained fatigue results were supported by metallographic analysis of cracks and corrosion scales. 


\section{Experimental procedures}

\subsection{Testing conditions}

Experiments were conducted in artificial seawater with a chemical composition according to ASTM $\mathrm{D} 1141$ (Table 1) at 1 bar $\mathrm{CO}_{2}$ and the flow rate of the $\mathrm{CO}_{2}$ gas was $250 \mathrm{ml} \mathrm{min}^{-1}$. The temperature of the solution was $20 \pm 3^{\circ} \mathrm{C}$. The solution was de-aerated in a de-aeration vessel by supplying oxygen free nitrogen gas until the oxygen content was lower than $5 \mathrm{ppb}$. The dissolved oxygen was measured by using optical oxygen sensor (Visiferm DO 225). Also the remaining setup was flushed with nitrogen in order to remove any oxygen. With the aim of obtaining an electrolyte with different concentrations of $\mathrm{Fe}^{2+}$, and consequently a range of different $\mathrm{pH}$, steel wool was exposed to deaerated seawater with 1 bar $\mathrm{CO}_{2}$ in the pre-corrosion vessel for different periods of time. Fatigue experiments were carried out with two initial $\mathrm{Fe}^{2+}$ concentrations, namely low $\left(440 \mathrm{mg} \mathrm{L}^{-1}\right.$ ) and high $\left(1000 \mathrm{mg} \mathrm{L}{ }^{-1}\right)$. The corresponding alkalinity $\left(\mathrm{HCO}_{3}{ }^{-}\right.$concentration) of the test solutions is shown in Table 2. The $\mathrm{Fe}^{2+}$ content was measured by a spectrophotometric method using a Shimadzu UV-1800 Spectrophotometer. The $\mathrm{pH}$ of the water taken from the vessel was measured using a pH meter (Radiometer Analytical pHC3081-8). The water free volume to steel area ratio was $20 \mathrm{ml} \mathrm{cm}^{-2}$.

Fatigue tests were performed with a constant $\mathrm{R}$ value (0.1) with two different stress ranges namely high (380 MPa) and medium (250 MPa) for tests performed with low and high initial $\mathrm{Fe}^{2+}$ content. An additional fatigue test at the low stress range (100 MPa) was performed for high initial $\mathrm{Fe}^{2+}$ content. Six rectangular specimens, with a length of $275 \mathrm{~mm}$, were tested at each stress range. The frequency used for fatigue testing was $0.5 \mathrm{~Hz}$ between 0 and $10^{6}$ cycles, while $2 \mathrm{~Hz}$ above $10^{6}$ cycle. Fatigue testing performed at high and medium stress ranges continued until the fracture occurred. Due to prolonged time needed for samples to fracture, the fatigue test performed at low stress range was continued for 2808 hours. Parameters used for fatigue tests are listed in Table 2. 
Additional fatigue tests were also performed in air for comparison. Air fatigue tests were performed with a stress range of $700 \mathrm{MPa}$. In order to compare results from air conditions with those generated in the corrosive media, regression of an S-N curve with a fixed slope of - 6 was used. ${ }^{42,47}$

\subsection{Test Setup}

The fatigue behavior of steel samples was analyzed by applying a deflection controlled four point bending test setup (see Fig. 1).

The deflection of the sample, $\delta$, in four point bending test is described by equation 1 , while generated stresses, $\sigma$, in the sample refer to equation 2 (Ref. 48).

$$
\begin{gathered}
\delta=\frac{M}{24 E I}\left(3 l^{2}-4 a^{2}\right) \\
\sigma=\frac{M}{I} \times \frac{h}{2}=\frac{12 E \delta h}{\left(3 l^{2}-4 a^{2}\right)}
\end{gathered}
$$

Where,

$M-$ bending moment

E-Young's modulus

$I=\frac{b h^{3}}{12}-$ second moment of area

$h$ - thickness of the sample

$l$ - distance between supports

$a$ - distance from the support to the loading point

The test setup was equipped with a de-aeration vessel, pre-corrosion vessel, and a special test chamber that made it possible to expose samples to the corrosive environment while testing them dynamically, ${ }^{2}$ see Fig. 2. All vessels were made of Duplex 2205, while tubings of AISI 316 L 
stainless steel, and the setup was constructed with the aim of avoiding ingress of oxygen in order to maintain a virtually oxygen free environment.

\subsection{Material and Specimen Preparation}

Six samples (length $275 \mathrm{~mm}$, width $12.5 \mathrm{~mm}$, thickness $4 \mathrm{~mm}$ ) were tested for each applied stress range and initial $\mathrm{Fe}^{2+}$ content of the solution. The total area of fatigue samples was $550 \mathrm{~cm}^{2}$. The material used for fatigue experiments was carbon steel with a composition of 0.77 wt-\% C, 0.24 wt\% Si, 0.65 wt-\% Mn, 0.17 wt-\% P, 0.06 wt-\% S, Fe as the balance. The material has a ferriticpearlitic microstructure. All experiments were performed on samples in as-received (i.e. cold rolling), conditions in order to simulate the material's behavior as in the flexible pipe, except that prior to each experiment, the surface of the samples was thoroughly degreased with petrol and acetone, cleansed with ethanol, and dried in a hot air flow. Due to cold rolling process, the microstructure of the material contained grains elongated in a longitudinal direction, which were oriented perpendicular to the applied load during fatigue testing.

\subsection{Corrosion assessment}

To measure the corrosion rate, six rectangular weight loss coupons (WLC) with a length of $91 \mathrm{~mm}$, width $12.5 \mathrm{~mm}$, and thickness $4 \mathrm{~mm}$, were placed in the test vessel. The total area of WLC's was $186 \mathrm{~cm}^{2}$. The WLC's were not subjected to dynamic loading. In addition, for each stress range for tests performed with high initial concentration, one fatigue sample (FS) was dedicated for descaling in order to analyze its corrosion rate under dynamic conditions. To measure the corrosion rate of WLC and FS the weight of each sample was measured before test and when the test was finished specimens were descaled with inhibited hydrochloric acid solution $(10 \% \mathrm{HCl}+0.4 \%$ Armohib 28) and their weight was determined again. 
To evaluate the morphology of the corrosion scales formed under dynamic conditions (for samples dynamically loaded), a scanning electron microscope (SEM Zeiss EVO MS10) was used. The corrosion scales were analyzed on both sides, where samples experienced tensile and compressive stresses during fatigue tests. Corrosion scale analysis was performed in locations where maximum stresses were applied during the fatigue testing. Phase analysis of the corrosion products was performed by means of X-ray Diffraction (XRD) by applying a Bruker AXS Diffractometer D8 Discover. Measurements were performed with Cr-Ka radiation and carried out on the surface of the samples resulting in a penetration depth of up to $17 \mu \mathrm{m}$.

\subsection{Crack Analysis}

To elucidate the mechanism of fatigue failure, cross section of one sample, exposed to each stress range and initial $\mathrm{Fe}^{2+}$ content of the solution was analyzed to observe the secondary cracks originating from the surface. The cracks were investigated on the both sides of the sample, where compressive and tensile stresses, respectively, were induced during fatigue testing. The average depth of the cracks was estimated based on the measurements of 10 cracks. The cracks were investigated using Light Optical Microscopy (LOM, Leica Dm Irm).

\section{Results}

\subsection{Fatigue Results}

The S-N plots, for samples exposed to solutions with a low and high initial $\mathrm{Fe}^{2+}$ concentration are shown in Fig. 3. Results from fatigue tests in air are included for comparison. Due to the confidentiality reasons the number of cycles could not be provided. However, a direct comparison can be made from the axis.

Fatigue results showed that when exposing samples to seawater at 1 bar $\mathrm{CO}_{2}$, fatigue life was decreased compared to the air conditions. Based on the fitted S-N curve for air fatigue results, with 
a fixed slope of -6 (see S-N line in Fig. 3), the fatigue life was approximately 7 and 33 times better in air than in corrosive media for high and medium stress ranges, respectively. In addition, two samples tested in air did not fracture despite of a relatively high stress range.

For samples tested under high stress range, the initial $\mathrm{Fe}^{2+}$ and $\mathrm{HCO}_{3}{ }^{-}$concentration in the solution, together with resulting $\mathrm{pH}$, did not affect the fatigue life significantly. Samples tested in a solution with a low and high initial $\mathrm{Fe}^{2+}$ concentration showed similar fatigue life (see Fig. 3).

At the medium stress range, the fatigue life of samples increased by a factor 4 and 5 for samples tested in a solution with a high and low $\mathrm{Fe}^{2+}$ content, respectively. In addition, the scatter in fatigue data was smaller compared to the loading at high stress range. The fatigue life of samples exposed to low $\mathrm{Fe}^{2+}$ content was approximately two times better than that of samples exposed to a solution with a high initial $\mathrm{Fe}^{2+}$ content. Fatigue tests in a solution with high $\mathrm{Fe}^{2+}$ concentration and low stress range did not fracture within the period of testing, and consequently, results are not included in the graph.

\subsection{Evolution of $\mathrm{pH}$ and $\mathrm{Fe}^{2+}$ Concentration}

The $\mathrm{Fe}^{2+}$ and $\mathrm{pH}$ (Fig. 4) analysis revealed for corrosion fatigue tests, that the trend of $\mathrm{pH}$ evolution followed deviations in $\mathrm{Fe}^{2+}$ concentrations as a direct consequence of changing the $\mathrm{HCO}_{3}{ }^{-}$ concentration in the solution. An increase in $\mathrm{Fe}^{2+}$ concentration, up to the maximum concentration of around $1400 \mathrm{mg} \mathrm{L}^{-1}$ (pH 6.3), took place when exposing samples to the solution with low initial $\mathrm{Fe}^{2+}$ content (Fig. $4 \mathrm{~A}$ and $\mathrm{C}$ ).

However, depending on the applied stress range, the maximum $\mathrm{Fe}^{2+}$ concentration and the maximum pH were reached after approximately 210 hours (Fig. 4 A) for the high stress range and after 430 hours (Fig. 4 C) for the medium stress range. Further exposure decreased the $\mathrm{Fe}^{2+}$ content 
to its final value of $1100 \mathrm{mg} \mathrm{L}^{-1}$ (pH 6.15) for high stress range and $800 \mathrm{mg} \mathrm{L}^{-1}$ (pH 6) for medium stress range.

In the corrosion fatigue test in the solution with high initial $\mathrm{Fe}^{2+}$ concentration at high and medium stress range (Fig. $4 \mathrm{~B}$ and $\mathrm{D}$, respectively), the $\mathrm{Fe}^{2+}$ content was relatively constant during the experiments $\left(\sim 1100 \mathrm{mg} \mathrm{L}^{-1}\right)$. The $\mathrm{pH}$ was also relatively stable at a value of $6.2(+/-0.1)$ at both stress ranges. For the test performed at the low stress range, the $\mathrm{Fe}^{2+}$ concentration started decreasing after approximately 480 hours of exposure reaching the final concentration of $300 \mathrm{mg} \mathrm{L}^{-}$ 1.

\subsection{Corrosion Scale Analysis}

Fig. 5 shows top view and cross section images of scales formed in corrosion fatigue tests in solutions with high initial $\mathrm{Fe}^{2+}$ concentration. Depending on the stresses present in the two sides (tensile or compressive), different morphologies of corrosion scales were apparent. The corrosion product formed on the compression side of the samples tested at high and medium stress range (Fig. 5 A and C) was not continuous and not well adherent. However, the top surface scale analysis (Fig. $5 \mathrm{~B}$ and D) revealed a compact scale with a rough surface topography for samples tested at both stress ranges. This indicates that due to the poor adhesion, the spallation of the corrosion scale, seen in Fig. $5 \mathrm{~A}$ and $\mathrm{C}$, might have occurred during the metallographic embedding process. When testing samples at the low stress range, the corrosion scale formed on the compression side was also poorly adherent and porous (Fig. 5 E).

Scales formed on the tension side of the samples (Fig. 5 G, I and K) were continuous and covered the whole surface of the samples at all stress ranges. The thickness of the corrosion scale was about $5 \mu \mathrm{m}$ at the high stress range, about $3 \mu \mathrm{m}$ at the medium stress range, and about $9 \mu \mathrm{m}$ at the low stress range. The XRD results showed that at all stress ranges, an iron carbonate $\left(\mathrm{FeCO}_{3}\right)$ film was 
formed (see Fig. 6 a, b and c). XRD analysis revealed also cementite $\left(\mathrm{Fe}_{3} \mathrm{C}\right)$ peaks. However, based on the homogenous morphology of the scales and XRD penetration depth of up to $17 \mu \mathrm{m}$, it is believed that $\mathrm{Fe}_{3} \mathrm{C}$ was measured from the substrate. Surface scale analysis (Fig. $5 \mathrm{H}, \mathrm{J}$, L) revealed relatively little topography and many cracks were observed after testing at high stress range (see arrows in Fig. $5 \mathrm{G}$ and $\mathrm{H}$ ). Fewer cracks in the scale were seen for samples tested at the medium stress range (see arrows in Fig. $5 \mathrm{I}$ and J) and the topography developed on the top of the primary corrosion layer appears to be more rough (Fig. $5 \mathrm{~J}$ ). No cracks were seen in the corrosion scale formed at the low stress range (Fig. 5 L), but the scale was not compact and contained pores (Fig. 5 $\mathrm{K})$.

In the fatigue test performed in a solution with low initial $\mathrm{Fe}^{2+}$ concentration, the corrosion scales were seen to have morphologies (Fig. 7) that differed from those formed with high initial $\mathrm{Fe}^{2+}$ content (Fig. 5). Formation of a double scale took place on both sides of the sample and at both stress ranges (Fig. 7 A, C, E and G). The corrosion scale consisted of an inner layer integrated with the substrate of the material and an outer layer, which was probably located above the original metal surface (see Fig. 7 A). Similarly to the samples tested in solutions with high initial $\mathrm{Fe}^{2+}$ content (Fig. 5 G, I and K), a continuous corrosion scale was formed on the tension side of the samples (Fig. $7 \mathrm{E}$ and $\mathrm{G}$ ), while scales with irregular thicknesses were developed on the compression sides (Fig. $7 \mathrm{~A}$ and $\mathrm{C}$ ). The $\mathrm{XRD}$ results showed that the corrosion scales formed on the tension side consisted of $\mathrm{FeCO}_{3}$ phase (see Fig. $6 \mathrm{~d}$ and e). At both stress ranges, the internal corrosion attack was deeper and the thickness of the outer layer was larger on the compression side of the sample than on the tension side (Fig. 7 A, C, E and G). The thickness of the outer corrosion scale, developed on the compression side as a function of the applied stresses. It was larger at high stress range (6-14 $\mu \mathrm{m})$ than at the medium stress range $(6-10 \mu \mathrm{m})$, see Fig. $7 \mathrm{~A}$ and $\mathrm{C}$, respectively. The corrosion scale showed poor adhesion to the surface on both sides and at both stress ranges. 
This was apparent from the gap at the interface between the inner and outer parts of the scale formed during metallographic preparation. An overview of the various morphologies of scales formed in solutions with low and high concentration of $\mathrm{Fe}^{2+}$ can be found in Table 3.

\subsection{Corrosion rates}

The corrosion rates for samples exposed to solutions with low and high initial $\mathrm{Fe}^{2+}$ concentration are shown in Fig. 8. Corrosion rates were based on weight loss coupons (WLC), which were not subjected to dynamic loading, however exposed together with fatigue tested samples (FS). The exposure time was directly related to the time needed for fatigue samples to fracture, and accordingly, relate to the applied stress ranges. The shortest exposure time of 1003 hours corresponds to the high stress range, whereas the longest exposure time of 2808 hours refers to the low stress range.

For tests performed at the high stress range (1003 hours), the corrosion rate of WLC, was approximately four times larger in solutions initially containing low $\mathrm{Fe}^{2+}$ concentration (75 $\mu \mathrm{m}$ year ${ }^{1}$ ) than in solutions with high initial $\mathrm{Fe}^{2+}$ content $\left(21 \mu \mathrm{m}\right.$ year $\left.^{-1}\right)$. Further, the corrosion rate for WLC tested in a solution with high initial $\mathrm{Fe}^{2+}$ content decreased with exposure time.

At high stress range (1003 hours), in the solution with high initial $\mathrm{Fe}^{2+}$ content, the fatigue sample (FS) had twice as large corrosion rate (40 $\left.\mu \mathrm{m} \mathrm{year}^{-1}\right)$ compared to the WLC $\left(21 \mu \mathrm{m}\right.$ year $\left.{ }^{-1}\right)$. The difference in corrosion rate between FS and WLC decreased with decreasing applied stress range. At low stress range (2808 hours), both FS and WLC experienced corrosion rates close to $10 \mu \mathrm{m}$ year $^{-1}$.

\subsection{Crack analysis}

Fig. 9 presents LOM images of secondary cracks formed in samples tested in solutions with a low and high initial $\mathrm{Fe}^{2+}$ concentration. It was apparent that the depth of the cracks and their appearance 
depended on the applied stress ranges, induced stresses in the sample, and the initial concentration of $\mathrm{Fe}^{2+}$ in the solution.

For samples tested in a solution with high initial $\mathrm{Fe}^{2+}$ content, sharp cracks were formed at the high stress range on both compression and tension sides (Fig. 9 A and B, respectively). The depth of the cracks was larger on the tension side $(625 \pm 364 \mu \mathrm{m})$ than on the compression side $(104 \pm 48 \mu \mathrm{m})$ (Table 4).

At medium stress range, no cracks were detected on the compression side (Fig. 9 C), while blunted cracks, with a depth of $20 \pm 6 \mu \mathrm{m}$, were developed on the tension side (Fig. 9 D). All cracks were filled with corrosion products (Fig. 9 A, B and D). No cracks were formed in the sample tested at the low stress range neither on the compression nor on the tension side (Fig. $9 \mathrm{E}$ and $\mathrm{F}$, respectively). It is likely that as a result of a long exposure time, the uneven surface seen on both sides (Fig. 9 E and F), was caused by the uniform corrosion of the sample.

The nature of the formed cracks appeared to be different for samples tested in a solution with low initial $\mathrm{Fe}^{2+}$ content compared to those formed in solutions with high initial $\mathrm{Fe}^{2+}$. For samples tested at the high stress range (Fig. $9 \mathrm{G}$ and $\mathrm{H}$ ), blunted cracks were formed on the compression and tension side of the sample (Fig. $9 \mathrm{G}$ and H, respectively). This is in contrast to the samples tested in a solution with high initial $\mathrm{Fe}^{2+}$ concentration (Fig. 9 A and B), where sharp cracks were observed. The local blunted cracks were deeper on the tension side $(43 \pm 10 \mu \mathrm{m})$ than on the compression side (26 $\pm 14 \mu \mathrm{m}$ ) of the sample (Fig. $9 \mathrm{G}$ and $\mathrm{H}$ ). At the medium stress range, no cracks were observed and the irregularities of the surface, seen on the compression and tension side, are believed to be caused by the uniform corrosion of the sample. 


\section{Discussion}

It was shown that by exposing samples to aqueous $\mathrm{CO}_{2}$ environment with various initial $\mathrm{Fe}^{2+}$ concentrations, the fatigue life of samples decreased by a factor of seven (high stress range) and 33 (medium stress range) compared to the air conditions. The reduction of fatigue life in aqueous $\mathrm{CO}_{2}$ environment has been also reported. ${ }^{37,38}$ It also has been reported ${ }^{27}$ that during testing in air, the fatigue rupture is associated with the localized plastic deformation, which leads to a crack development and its propagation. The crack initiation occurs most frequently from stress concentrations at the surface, like at corners or holes, or microscopic features like slip bands. ${ }^{27,29}$ In the corrosive media, due to the local film breakdown, as a consequence of mechanical and/or chemical effect, or local micro galvanic effect, the localized corrosion (pitting) occurs. ${ }^{27,28,38}$ Pits work as stress raisers to reach the stress level above the yield strength of the material, ${ }^{27,38}$ consequently leading to premature fatigue failure, compared to air conditions.

By exposing samples to solutions with low and high initial $\mathrm{Fe}^{2+}$ content, a significant difference in the scale formation was seen when analyzing the compression and tension sides of the samples. In solutions with high and low $\mathrm{Fe}^{2+}$ content, a continuous and compact scale was formed on the tension side, while a scale with irregular thickness and poor adhesive properties developed on the compression side. It has been reported ${ }^{49,50}$ that the compressive stresses may cause spallation of the oxide scale due to buckling or wedging. It is expected that the same phenomenon was seen on the compression side of the samples in the present study. Due to inducement of compressive strains during dynamic loading, buckling of the scale might have taken place, resulting in its poor adhesion. However, the tension side of the sample showed a continuous corrosion scale in solutions with low and high initial $\mathrm{Fe}^{2+}$ content. It is expected that the tensile stresses caused cracking of the scale but without spallation. This is in a good agreement with the reported results, ${ }^{49}$ where no spallation of the scale was seen when applying tensile stresses. 
The solubility limit of $\mathrm{FeCO}_{3}$ for 1 bar $\mathrm{CO}_{2}$ at $20{ }^{\circ} \mathrm{C}$ is $202 \mathrm{mg} \mathrm{L}^{-1}$ (Ref.51). It means that the supersaturation of $\mathrm{Fe}^{2+}$ was present when testing samples in solutions initially containing low concentration of $\mathrm{Fe}^{2+}$, while a highly supersaturated condition was present for tests with high $\mathrm{Fe}^{2+}$ content. Corrosion rate results, which were in a good agreement with the scale analysis, revealed that the samples exposed to the solution with low initial $\mathrm{Fe}^{2+}$ content, experienced four times higher corrosion rates compared to the samples tested in high initial $\mathrm{Fe}^{2+}$. The higher corrosion rate of the samples tested with low initial $\mathrm{Fe}^{2+}$ content was most likely due to the lower degree of $\mathrm{Fe}^{2+}$ supersaturation and consequently slower kinetics of $\mathrm{FeCO}_{3}$ formation. ${ }^{52}$ Due to higher supersaturation of $\mathrm{Fe}^{2+}$ seen in the test performed with high initial $\mathrm{Fe}^{2+}$ content, the rate of $\mathrm{FeCO}_{3}$ scale formation was higher, ${ }^{52}$ compared to the test executed with low $\mathrm{Fe}^{2+}$. It means that the whole surface was likely to be covered with a protective scale acting as a barrier for inward diffusion of corrosive species reducing the dissolution of the metal. ${ }^{53,54}$ This was reflected in the low corrosion rates seen for samples tested in solutions with high initial $\mathrm{Fe}^{2+}$ concentration.

It has been reported ${ }^{51}$ that in the load free conditions, a decrease in $\mathrm{Fe}^{2+}$ concentration was directly related to a decrease of corrosion rate of samples and is two times faster for solutions initially containing $1300 \mathrm{mg} \mathrm{L}^{-1}$ of $\mathrm{Fe}^{2+}$ compared to $370 \mathrm{mg} \mathrm{L}^{-1}$ of $\mathrm{Fe}^{2+}$. This is in contrast to the current results, where a decrease in $\mathrm{Fe}^{2+}$ concentration occurred after 429 hours (high stress range) and 523 hours (medium stress range) for samples tested in solutions initially containing low $\mathrm{Fe}^{2+}$, while no decrease in $\mathrm{Fe}^{2+}$ concentration was seen when the test was performed with high initial $\mathrm{Fe}^{2+}$. This indicates that even though samples tested with high initial $\mathrm{Fe}^{2+}$ experienced low corrosion rates of $40 \mu \mathrm{m}$ year $^{-1}$ (high stress range) and $20 \mu \mathrm{m} \mathrm{year}^{-1}$ (medium stress range), the scale did not become more protective with increased exposure time. Consequently, it is believed that in the corrosion fatigue, not only the kinetics of $\mathrm{FeCO}_{3}$ formation play an important role in ensuring protective properties of the corrosion scale, but also the resistance of the corrosion layer towards applied 
stresses. Scale analysis revealed formation of a compact corrosion scale with good adhesive properties on the tension side of the samples tested in solutions with high initial $\mathrm{Fe}^{2+}$ content. It is probable that due to a very good adherence of the corrosion scale, tensile stresses induced in the material during fatigue testing could be transferred to the corrosion layer. Due to lower tensile strength of $\mathrm{FeCO}_{3}$, compared to the steel, breaking of the scale took place resulting in visible scale cracks formed at the high and medium stress ranges. Due to the localized scale defects, mass transfer of corrosive species such as $\mathrm{CO}_{3}{ }^{2-}$ and $\mathrm{HCO}_{3}{ }^{-}$to the steel surface and their reaction with the metal substrate, causing slow but constant dissolution of the steel, was possible. This explains the missing decrease of $\mathrm{Fe}^{2+}$ concentration as a function of exposure time. The hypothesis about the negative impact of the stresses on the protective properties of the scale was confirmed by the results from the test performed at the low stress range. Results revealed that when decreasing the stress range to $100 \mathrm{MPa}$, the concentration of $\mathrm{Fe}^{2+}$ started to decrease already after approximately 480 hours. It is in a good agreement with the reported results, ${ }^{51}$ where in the load free conditions, a decrease of $\mathrm{Fe}^{2+}$ concentration was seen after approximately 440 hours.

Corrosion scales formed in solutions with low initial $\mathrm{Fe}^{2+}$ content revealed poor adhesion to the surface as it was apparent from the gap at the interface between the inner and outer parts of the scale. It is likely that due to the poor contact between the upper layer of the scale and the substrate of the material, the scale was more flexible during fatigue testing. It is therefore expected that the tensile stresses induced in the material were not as easily transferred to the corrosion scale as to the well adherent corrosion layer formed in solutions with high initial $\mathrm{Fe}^{2+}$ concentration. This hypothesis is supported by the top scale analysis, where no scale cracks were revealed. It means that the corrosion scale could become more protective with exposure time, which was reflected by a decreasing $\mathrm{Fe}^{2+}$ concentration. 
Analysis of the secondary cracks revealed crack blunting for specimens tested at high stress range in a solution with low initial $\mathrm{Fe}^{2+}$ content. It is believed that the crack blunting occurred due to high initial corrosion rates. As a consequence of the reduction of the stresses at the crack tip, further crack propagation was retarded. ${ }^{27,32,55}$ This is in contrast to the sharp and up to 10 times deeper cracks developed in solutions with high initial $\mathrm{Fe}^{2+}$ concentration. Due to too slow corrosion rate, the region around the crack was not corroded away and the crack could propagate deeper.

Based on the secondary crack analysis, samples tested in solutions with low initial $\mathrm{Fe}^{2+}$ content could have shown longer fatigue life compared to the samples tested in high initial $\mathrm{Fe}^{2+}$. However, despite the clear differences in the corrosion rate and crack morphology, the same fatigue life at the high stress range. The effect might be attributed to the way in which the stress is applied during four point bending test. Fatigue testing was performed with a deflection controlled test setup and the deflection of the sample was constant during the whole test. Samples, which experienced deep and sharp cracks in solutions with high initial $\mathrm{Fe}^{2+}$ content were consequently subjected to a greater reduction in thickness compared to the samples which developed blunted cracks in a solution with low initial $\mathrm{Fe}^{2+}$. By maintaining a constant deflection $(\delta)$, throughout the whole test, the stresses induced in the samples depend linearly on the changes of the thickness of the samples based on equation 2.

Due to deeper cracks formed in samples exposed to high initial $\mathrm{Fe}^{2+}$ concentration, the resulting stresses were smaller than for the samples exposed to solutions with low initial $\mathrm{Fe}^{2+}$. However, the shape of the crack tip played an important factor on the local development of the stresses as well. Due to the crack blunting seen for samples tested in a solution with low initial $\mathrm{Fe}^{2+}$ content, the stress concentrations at the crack tip were less severe compared to the stresses at the sharp crack tip developed in solutions with high initial $\mathrm{Fe}^{2+}$. Accordingly, by combining the changes of the overall stresses due to the thickness reduction of the samples with the local stresses dependent on the 
shapes of the crack tips, it is likely that the resulting stresses were similar for both samples, which might explain their comparable fatigue life.

Fatigue results from the medium stress range, revealed that samples exposed to the solution with low initial $\mathrm{Fe}^{2+}$ had two times longer fatigue life than samples tested in high initial $\mathrm{Fe}^{2+}$. Analysis of the secondary cracks revealed formation of local, blunted cracks on the tension side of the samples tested in high initial $\mathrm{Fe}^{2+}$ conditions. This was in a clear contrast to the sharp and 30 times deeper cracks developed at the high stress range. As a consequence of the scale cracking, the solution had a local access to the micro cracks. Due to lower stresses and accordingly longer time needed for samples to fracture, the solution had enough time to react with the material, which resulted in blunting of the cracks. Samples tested in a solution with low initial $\mathrm{Fe}^{2+}$, did not reveal apparent cracks and the uneven surface of the sample is believed to be caused by the corrosion of the sample. The corrosion rate is not known for samples tested at the medium stress range in a solution with low initial $\mathrm{Fe}^{2+}$ content. However, based on the increasing $\mathrm{Fe}^{2+}$ concentration of the solution at the medium stress range, which clearly indicates dissolution of the material, as well as corrosion rates data reported in, ${ }^{51}$ it is expected that samples tested in a solution with low initial $\mathrm{Fe}^{2+}$ had higher initial corrosion rate compared to the samples tested with high initial $\mathrm{Fe}^{2+}$. As a result of lower stresses and higher corrosion rates, it is believed that even though micro cracks were formed, they were quickly blunted by the corrosion process.

Due to shallow blunted cracks formed in solutions with high initial $\mathrm{Fe}^{2+}$, it is likely that the thickness reduction of the sample did not play a significant role on the stresses induced in the sample. It is therefore suggested that the stresses at the crack tip mostly influenced the crack propagation. The absence of the blunted cracks for samples tested in a solution with low initial $\mathrm{Fe}^{2+}$ concentration, resulted in lower local stresses compared to the regions, where local blunted cracks were formed in a solution with high initial $\mathrm{Fe}^{2+}$. It is probable that the crack propagation took 
longer time for samples tested in a solution with low initial $\mathrm{Fe}^{2+}$ resulting in longer fatigue life compared to the samples tested in a solution with high initial $\mathrm{Fe}^{2+}$.

No apparent cracks were seen for samples tested in a solution with high initial $\mathrm{Fe}^{2+}$ at low stress range, where only uniform corrosion of the surface was seen. Corrosion rate results showed that the effect of stresses on the corrosion rate of samples was decreasing with decreasing stress range. Results revealed that samples tested at low stress range behaved like in load free conditions, which was reflected in a similar corrosion rate of fatigue samples and weight loss coupons. It indicates that the impact of stresses on the protective properties of the corrosion scale was much less severe compared to the effect seen at the high and medium stress ranges. There are no results available between the medium and low stress ranges. It is therefore likely that cracks also would be absent at stress ranges higher than $100 \mathrm{MPa}$. Results indicate that at low stress ranges (based on the current results $<100 \mathrm{MPa}$ ) fast kinetics of scale formation, facilitated by the high initial supersaturation of $\mathrm{Fe}^{2+}$ in the solution, and consequently low corrosion rates, help to avoid local pits formation and will have more beneficial impact on the fatigue life of steel armours. It is in contrast to the solutions with initial $\mathrm{Fe}^{2+}$ concentrations marginally above the solubility limit of $\mathrm{Fe}^{2+}$, where the initial corrosion rate is faster and the surface is rougher, so that higher local stresses are expected.

Most of flexible pipes operate at stress ranges of approximately $100 \mathrm{MPa}$ for most load cases. The fatigue life estimated by the corrosion fatigue testing on the laboratory scale at the stress ranges above $100 \mathrm{MPa}$ is still conservative compared to the real fatigue behavior of metal wires in flexible pipes. It was shown that samples tested in a solution with high initial $\mathrm{Fe}^{2+}$ at low stress range experienced the same corrosion rate as samples not subjected to dynamic loading. It indicates that at low stress range the contribution of the applied stresses to the overall corrosion fatigue behavior of steel armours is smaller compared to the impact of the corrosive environment. This contradicts the situation at high stress ranges (> $250 \mathrm{MPa}$ ), where it was shown that the stresses had a larger impact 
on the protective properties of the corrosion scale and in order to improve fatigue life of steel armours, high initial corrosion rates are necessary to retard crack propagation. It is therefore believed that the beneficial impact of the initial high supersaturation of $\mathrm{Fe}^{2+}$, seen in the annulus, on the fatigue life steel armours occurs first at the stress range below $100 \mathrm{MPa}$.

\section{Conclusion}

Based on the above results the following conclusions can be drawn:

1. The type of induced stresses in the sample, compressive or tensile, influence the morphology of the corrosion scales. A continuous corrosion scale was formed on the tension side, while an irregular corrosion layer was formed on the compression side of the sample.

2. Scale analysis revealed that adhesion of the corrosion scale plays an important role in the resistance of the scale towards applied stresses. Results showed that poorly adhesive scales formed in solutions with an initial $\mathrm{Fe}^{2+}$ of $440 \mathrm{mg} \mathrm{L}^{-1}$ had better resistance towards applied stresses compared to well adherent scales formed in $1000 \mathrm{mg} \mathrm{L}^{-1}$ of $\mathrm{Fe}^{2+}$.

3. Fatigue results showed that there was no effect of the initial $\mathrm{Fe}^{2+}$ concentration on the fatigue life of steel armours at the stress range of $380 \mathrm{MPa}$.

4. Secondary crack analysis showed that at the stress range of $250 \mathrm{MPa}$, the initial high corrosion rate of samples in solutions with an initial $\mathrm{Fe}^{2+}$ content of $440 \mathrm{mg} \mathrm{L}^{-1}$ was beneficial for the crack retardation and, consequently, the fatigue life of steel. 
5. Results revealed that the negative effect of applied stresses on the protective properties of the corrosion scale decreased with decreasing applied stresses. Corrosion rate results in relation to the evolution of the $\mathrm{Fe}^{2+}$ concentration showed that the fatigue sample at stress range of $100 \mathrm{MPa}$ fatigue sample experienced the same corrosion rate as samples not subjected to dynamic loading.

6. It is suggested that at low stress ranges $(<250 \mathrm{MPa})$, high initial supersaturation of $\mathrm{Fe}^{2+}$, seen in annulus, reduces the probability of pit formation and consequently might have a more beneficial effect on the fatigue life of steel armours compared to the solutions with $\mathrm{Fe}^{2+}$ content marginally above the solubility limit of $\mathrm{FeCO}_{3}$.

\section{Acknowledgments}

The authors would like to acknowledge InnovationsFonden in Denmark for providing financial support of the project.

\section{References}

[1] A. Rubin and J. Gudme: 'Qualification of Steel Wire for Flexible Pipes', NACE International, Houston, TX, March 2006, Paper 06149.

[2] A. Rubin and J. Gudme: 'Test method for corrosion fatigue testing of cold rolled steel wire in sour and sweet environment based on deflection controlled four point bending', NACE International, Houston, TX, March 2009, Paper 09103.

[3] A. Rubin, S. Overby, T. S. Nielsen, M. Haahr, J. Gudme: 'Corrosion rates of carbon steel in confined environments', NACE International, Houston, TX, March 2012, Paper 01495. 
[4] E. Remita, F. Ropital, J. Kittel: 'Experimental and Theoretical Investigation of the Uniform Corrosion in the Annulus of Offshore Flexible Pipelines', NACE International, Houston, TX, March 2008, Paper 08538.

[5] T. Berntsen, M. Seiersten, T. Hemmingsen: 'Effect of $\mathrm{FeCO}_{3}$ Supersaturation and Carbide Exposure on the $\mathrm{CO}_{2}$ Corrosion Rate of Carbon Steel', Corrosion, 2013, 69, 601-613.

[6] M. Henriquez, N. Pébère, N. Ochoa, A. Viloria: 'Electrochemical Investigation of the Corrosion Behavior of API 5L-X65 Carbon Steel in Carbon Dioxide Medium', Corrosion, 2013, 69, 1171-1179.

[7] A. Dugstad: 'The Importance of $\mathrm{FeCO}_{3}$ Supersaturation on the $\mathrm{CO}_{2}$ Corrosion of Carbon Steels', NACE International, Houston, TX, March 1992, Paper 14.

[8] G. Lin, M. Zheng, Z. Bai, X. Zhao: 'Effect of Temperature and Pressure on the Morphology of Carbon Dioxide Corrosion Scales', Corrosion, 2006, 62, 501- 507.

[9] M. Nordsveen, S. Nešić, R. Nyborg, A. Stangeland: 'A Mechanistic Model for Carbon Dioxide Corrosion of Mild Steel in the Presence of Protective Iron Carbonate Films-Part 1: Theory and Verification', Corrosion, 2003, 59, 443-456.

[10] V. Ruzic, M. Veidt, S. Nešić: 'Protective Iron Carbonate Films-Part 3: Simultaneous ChemoMechanical Removal in Single-Phase Aqueous Flow', Corrosion, 2007, 63, 758-769.

[11] J. Han, B. N. Brown, S. Nešić: 'Investigation of the Galvanic Mechanism for Localized Carbon Dioxide Corrosion Propagation Using the Artificial Pit Technique', NACE International, Houston, TX, March 2007, Paper 07323.

[12] A. Dugstad: 'Mechanism of Protective Film Formation During $\mathrm{CO}_{2}$ Corrosion of Carbon Steel', NACE International, Houston, TX, March 1998, Paper 31.

[13] W. Sun, S. Nešić, R. C. Woollam: 'The effect of temperature and ionic strength on iron carbonate $\left(\mathrm{FeCO}_{3}\right)$ solubility limit', Corros. Sci., 2009, 51, 1273-1276. 
[14] S. Nešić: 'Key issues related to modelling of internal corrosion of oil and gas pipelines - A review', Corros. Sci., 2007, 49, 4308-4338.

[15] S. Nešić, G. T. Solvi, J. Enerhaug: 'Comparison of the Rotating Cylinder and Pipe Flow Tests for Flow-Sensitive Carbon Dioxide Corrosion', Corrosion, 1995, 51, 773-787.

[16] V. Ruzic, M. Veidt, S. Nešić: 'Protective Iron Carbonate Films—Part 1: Simultaneous ChemoMechanical Removal in Single-Phase Aqueous Flow', Corrosion, 2007, 63, 758-769.

[17] S. Nešić: 'An Electrochemical Model for Prediction of Corrosion of Mild Steel in Aqueous Carbon Dioxide Solutions', Corrosion, 1996, 52, 280-294.

[18] D. A. López, W.H. Schreiner, S.R. Sanchez, S. N. Simison: 'The influence of carbon steel microstructure on corrosion layers. An XPS and SEM characterization', Appl. Sur. Sci., 2003, 207, 69-85.

[19] D. A. López, S. N. Simison, S.R. Sanchez: 'EIS studies on the inhibition efficiency of benzimidazole', Electrochim.Acta, 2003, 48, 845-854.

[20] M. Ueda, A. Ikeda: 'Effect of Microstructure and Cr Content in Steel on $\mathrm{CO}_{2}$ Corrosion', NACE International, Houston, TX, March 1996, Paper 99013.

[21] K. Videm, A. Dugstad: 'Corrosion of carbon steel in an aqueous carbon dioxide environment. II: Film formation', Mater. Performance, 1989, 28, 46-50.

[22] K. Videm, A. Dugstad: 'Corrosion of carbon steel in an aqueous carbon dioxide environment. I: Solution effects', Mater. Performance, 1989, 28, 63-67.

[23] W. Sun, S. Nešić: 'Kinetics of Corrosion Layer Formation: Part 1-Iron Carbonate Layers in Carbon Dioxide Corrosion', Corrosion, 2008, 64, 334-346.

[24] R. Nyborg, A. Dugstad: 'Mesa Corrosion Attack in Carbon Steel and 0.5 \% Chromium Steel', NACE International, Houston, TX, March 1998, Paper 29. 
[25] M. B. Kermani, A. Morshed: 'Carbon Dioxide Corrosion in Oil and Gas Production-A Compendium', Corrosion, 2003, 59, 659-683.

[26] R. Baboian: 'Corrosion Tests and Standards: Application and Interpretation. Environmental Cracking-Corrosion Fatigue', ASTM International, 2005.

[27] R. Akid: 'Corrosion fatigue', Shreir’s Corrosion, 2010, 928-953.

[28] Y. Z. Wang: 'Corrosion Fatigue', Uhlig’s Corrosion Handbook, $3^{\text {rd }}$ edn, 2011, 195-202.

[29] S. Suresh: 'Fatigue of Materials', $2^{\text {nd }}$ edn, 1998, United Kingdom, Cambridge University Press.

[30] A. Félix-Henry: 'Prevention and Monitoring of Fatigue-Corrosion of Flexible Risers' Steel Reinforcements', Proceedings of the $26^{\text {th }}$ International Conference on Offshore Mechanics and Arctic Engineering, San Diego, California, US, June 2007, Paper 29186.

[31] D. Baxter: 'Corrosion fatigue of steel catenary risers in sweet production', Proceedings of the International Conference on Offshore Mechanics and Arctic Engineering, Estoril, Portugal, June 2008, Paper 57075.

[32] R. van der Velden, H. L. Ewalds, W. A. Schultze, A. Punter: 'Anomalous Fatigue Crack Growth Retardation in steels for Offshore Applications', Corrosion Fatigue: Mechanics, Metallurgy, Electrochemistry, and Engineering, ASTM STP 801, T. W. Crooker and B. N. Leis Eds., American Society for Testing and Materials, 1983, 64-80.

[33] P. M. Scott: 'Chemistry Effects in Corrosion Fatigue', Corrosion Fatigue: Mechanics, Metallurgy, Electrochemistry, and Engineering, ASTM STP 801, T. W. Crooker and B. N. Leis Eds., American Society for Testing and Materials, 1983, 319-350.

[34] R. Mathis: 'Initiation and early growth mechanisms of corrosion fatigue cracks in stainless steels', J. Mater.Sci., 1987, 22, 907-914. 
[35] R. P. Gangloff: 'Corrosion fatigue crack propagation in metals', National Aeronautics and Space Administration, Office of Management, Scientific and Technical Information Division, 1990.

[36] J. H. Xie: 'A mechanism for the crack initiation of corrosion fatigue of Type 316L stainless steel in Hank’s solution', Mater.Charact., 2002, 48, 271-277.

[37] T. R. Andersen: 'Corrosion Fatigue of Steel Armours in Flexible Risers', Proceedings of the International Conference on Offshore Mechanics and Arctic Engineering, Oslo, Norway, June 2002, Paper 28052.

[38] A. Pfennig, R. Wiegand, M. Wolf, C.-P. Bork: 'Corrosion and corrosion fatigue of AISI 420C (X46Cr13) at $60^{\circ} \mathrm{C}$ in $\mathrm{CO}_{2}$-saturated artificial geothermal brine', Corros.Sci., 2013, 68, 134 143.

[39] F. Santos, F. Pires, R. Clements, J. Clevelario, T. Sheldrake, L. F. G. de Souza, P. P. Kenedi: 'Corrosion Fatigue Behavior of Flexible Pipe Tensile Armor Wires in $\mathrm{CO}_{2}$ Environment', Mat.Sci.Forum, 2013, 758, 77-82.

[40] R. Pelloux, J. M. Genkin: 'Corrosion Fatigue', Fatigue of Materials and Structures: Fundamentals, 2010, 377-399.

[41] C. T. Fujii, J. A. Smith: 'Environmental Influences on the Aqueous Fatigue Crack Growth Rates of HY-130 Steel', Corrosion Fatigue: Mechanics, Metallurgy, Electrochemistry, and Engineering, ASTM STP 801, T. W. Crooker and B. N. Leis Eds., American Society for Testing and Materials, 1983, 390-402.

[42] S. Berge, E. Bendiksen, J. Gudme, R. Clements: 'Corrosion Fatigue Testing of Flexible Riser Armour: Procedures for Testing and Assessment of Design Criteria', Proceedings of the International Conference on Offshore Mechanics and Arctic Engineering, Cancun, June 2003, Paper 37327. 
[43] F. Grealish, R. Smith, J. Zimmerman: 'New Industry Guidelines for Fatigue Analysis of Unbonded Flexible Risers', Offshore Technology Conference, May 2006, Paper 18303.

[44] S. Berge, N. K. Langhelle, T. G. Eggen: 'Environmental Effects on Fatigue Strength of Armour Wire for Flexible Risers', Proceedings of the International Conference on Offshore Mechanics and Arctic Engineering, Estoril, Portugal, June 2008, Paper 57132.

[45] E. Trillo, R. D. Kane, A. Ethridge, R. Clements: 'Corrosion Fatigue Testing of Armor Wire Materials in Subsea Environments', NACE International, Houston, TX, March 2007, Paper 07103.

[46] P. Mehdizadeh, R.L. Mcglasso, J.E. Landers: 'Corrosion fatigue performance of a carbon steel in brine containing air, $\mathrm{H}_{2} \mathrm{~S}$ and $\mathrm{CO}_{2}$ ', Corrosion, 1966, 22, 325-335.

[47] N. K. Langhelle, S. Berge, R. Igland: ' Joint Industry Project: Corrosion Fatigue of Armour Wire for Flexible Pipes - Phase I Testing in sweet Environments', Norwegian Marine Technology Research Institute, 2003, Report 700120.

[48] W. A. Brantley, T. Eliades: 'Orthodontic Materials: Scientific and Clinical Aspects', 2011, page 35.

[49] K. Pantleon: 'Phase identification and internal stress analysis of steamside oxides on superheater tubes by means of X-ray diffraction', Metall.Mater.Trans.A, 2011, 41A,

[50] M. Schütze, D. R. Holmes: 'Protective oxide scales and their breakdown', Institute of corrosion Wiley, 1997.

[51] M. Rogowska, J.Gudme, A.Rubin, K.Pantleon, R.Ambat: 'The effect of Fe ion concentration on corrosion of carbon steel in $\mathrm{CO}_{2}$ environment': Accepted in Corrosion Engineering, Science and Technology, $1^{\text {st }}$ of May 2015, available online.

[52] A. Dugstad: 'Fundamental Aspects of $\mathrm{CO}_{2}$ Metal Loss Corrosion - Part 1: Mechanism', NACE International, Houston, TX, March 2006, Paper 06111. 
[53] J. B. Sun, G.A. Zhang, W.Liu, M.X. Lu: 'The formation mechanism of corrosion scale and electrochemical characteristic of low alloy steel in carbon dioxide-saturated solution', Corr.Sci., 2012, 57, 131-138.

[54] G. Schmitt, M.Horstemeier: 'Fundamental Aspects of $\mathrm{CO}_{2}$ Metal Loss Corrosion - Part II: Influence of Different Parameters on $\mathrm{CO}_{2}$ Corrosion Mechanisms', NACE International, Houston, TX, March 2006, Paper 06112.

[55] J. C. Radon: 'Crack blunting and arrest in corrosion fatigue of mild steel', Int.J.Fracture, 1976, 12, 467-469.

\section{List of table captions}

Table 1 Chemical composition of Seawater (ASTM D1141).

Table 2 Details of the test conditions.

Table 3 The overview of the morphology of the scales formed in solutions containing initially 1000 $\mathrm{mg} \mathrm{L}^{-1}$ and $440 \mathrm{mg} \mathrm{L}^{-1}$ of $\mathrm{Fe}^{2+}$ (based on Fig. 5 and Fig. 7).

Table 4 The depth of the cracks, measured on cross sections (Fig. 9) of samples tested in corrosion fatigue at the stress ranges of $380 \mathrm{MPa}, 250 \mathrm{MPa}$ and $100 \mathrm{MPa}$ in a solution with an initial $\mathrm{Fe}^{2+}$ of $440 \mathrm{mg} \mathrm{L}^{-1}$ and $1000 \mathrm{mgL}^{-1}$.

\section{List of figure captions}

Fig. 1 Schematic illustration of a four point bending setup used for corrosion fatigue testing.

Fig. 2. Schematic drawing of the test set-up for corrosion fatigue testing: (A) De-aeration chamber, (B) Pre-corrosion chamber, (C) Test chamber ((1) Fatigue sample, (2) Eccentric, (3) Wash bottle). 
Fig. 3. Stress range as a function of fatigue life of samples exposed to air and seawater with 1 bar $\mathrm{CO}_{2}$ with initial $\mathrm{Fe}^{2+}$ concentration of $440 \mathrm{mg} \mathrm{L}^{-1}$ and $1000 \mathrm{mg} \mathrm{L}^{-1}$.

Fig. 4. The $\mathrm{pH}$ and $\mathrm{Fe}^{2+}$ development as a function of exposure time for corrosion fatigue tests performed at 1 bar $\mathrm{CO}_{2}$ and stress range of $380 \mathrm{MPa}(\mathrm{A}, \mathrm{B}), 250 \mathrm{MPa}(\mathrm{C}, \mathrm{D})$ and $100 \mathrm{MPa}(\mathrm{E})$ with solutions with an initial $\mathrm{Fe}^{2+}$ of $440 \mathrm{mg} \mathrm{L}^{-1}(\mathrm{~A}, \mathrm{C})$ and $1000 \mathrm{mg} \mathrm{L}^{-1}(\mathrm{~B}, \mathrm{D}, \mathrm{E})$.

Fig. 5. SEM images of corrosion scales buildup during fatigue test in seawater saturated with 1 bar $\mathrm{CO}_{2}$ and initial $\mathrm{Fe}^{2+}$ of $1000 \mathrm{mgL}^{-1}$. Images present corrosion scales developed on the compression and tension side at $380 \mathrm{MPa}, 250 \mathrm{MPa}$ and $100 \mathrm{MPa}$.

Fig. 6. XRD phase analysis for corrosion scales formed on the tension side of fatigue samples tested in solution with initial $\mathrm{Fe}^{2+}$ of $1000 \mathrm{mg} \mathrm{L}^{-1}$ at (a) $100 \mathrm{MPa}$, (b) $250 \mathrm{MPa}$, (c) $380 \mathrm{MPa}$; and $\mathrm{Fe}^{2+}$ of $440 \mathrm{mg} \mathrm{L}^{-1}$ at (d) $250 \mathrm{MPa}$ and (e) $380 \mathrm{MPa}$. Arrows mark two overlapping peaks representing $\mathrm{FeCO}_{3}$ phase

Fig. 7. SEM images of corrosion scales built during corrosion fatigue test in Seawater at 1 bar $\mathrm{CO}_{2}$ and initial $\mathrm{Fe}^{2+}$ of $440 \mathrm{mg} \mathrm{L}^{-1}$. Images present corrosion scales developed on the tension and compression sides for the stress ranges of $380 \mathrm{MPa}$ and $250 \mathrm{MPa}$.

Fig. 8. Corrosion rates, based on weight loss coupons (WLC), which were not subjected to dynamic loading, and fatigue samples (FS) tested dynamically, for tests performed at stress ranges of $380 \mathrm{MPa}$ (1003 hours), 250MPa (1256 hours) and $100 \mathrm{MPa}$ (2808 hours) in solutions with initial $\mathrm{Fe}^{2+}$ of $440 \mathrm{mg} \mathrm{L}^{-1}$ and $1000 \mathrm{mg} \mathrm{L-}{ }^{1}$.

Fig. 9. LOM images of cracks formed for samples tested in corrosion fatigue at stress ranges of 380 MPa, $250 \mathrm{MPa}$ and $100 \mathrm{MPa}$ in solutions with an initial $\mathrm{Fe}^{2+}$ of $440 \mathrm{mg} \mathrm{L}^{-1}$ and $1000 \mathrm{mg} \mathrm{L}^{-1}$. 
Table 1 Chemical composition of Seawater (ASTM D1141).

\begin{tabular}{|c|c|c|c|c|c|c|c|c|c|c|}
\hline & $\mathrm{NaCl}$ & $\mathrm{MgCl}_{2}$ & $\mathrm{Na}_{2} \mathrm{SO}_{4}$ & $\mathrm{CaCl}_{2}$ & $\mathrm{KCl}$ & $\mathrm{NaHCO}_{3}$ & $\mathrm{KBr}$ & $\mathrm{H}_{3} \mathrm{BO}_{3}$ & $\mathrm{SrCl}_{2}$ & $\mathrm{NaF}$ \\
\hline $\begin{array}{c}\text { Composition } \\
\left(\mathrm{mg} \mathrm{L}^{-1}\right)\end{array}$ & 24530 & 5200 & 4090 & 1160 & 695 & 201 & 101 & 27 & 25 & 3 \\
\hline
\end{tabular}

Table 2 Details of the test conditions.

\begin{tabular}{ccccccc}
\hline Base solution & $\begin{array}{c}\text { Stress range } \\
(\mathrm{MPa})\end{array}$ & $\begin{array}{c}\mathrm{Fe}^{2+} \\
\left(\mathrm{mg} \mathrm{L}^{-1}\right)\end{array}$ & $\begin{array}{c}\mathrm{HCO}_{3}^{-} \\
\left(\mathrm{mg} \mathrm{L}^{-1}\right)\end{array}$ & $\mathrm{pH}$ & $\begin{array}{c}\text { Oxygen } \\
(\mathrm{ppb})\end{array}$ & $\begin{array}{c}\text { Corresponding } \\
\text { exposure time } \\
(\mathrm{h})\end{array}$ \\
\hline Artificial & 380 & 440,1000 & 1005,2170 & $5.7,6.2$ & & 1003 \\
Seawater & 250 & 440,1000 & 1005,2170 & $5.7,6.2$ & $<5$ & 1256 \\
Air & 100 & 1000 & 2170 & 6.2 & & 2808 \\
\hline
\end{tabular}

Table 3 The overview of the morphology of the scales formed in solutions containing initially $1000 \mathrm{mg} \mathrm{L}^{-1}$ and $440 \mathrm{mg} \mathrm{L}^{-1}$ of $\mathrm{Fe}^{2+}$ (based on Fig. 5 and Fig. 7).

\begin{tabular}{c|c|c|c}
$\begin{array}{c}\text { Initial Fe } \\
\mathrm{mg} \mathrm{L}^{-1}\end{array}$ & $\begin{array}{c}\text { Stress range } \\
{[\mathrm{MPa}]}\end{array}$ & Compression side & Tension side \\
\hline 1000 & 380 & $\begin{array}{c}\text { poorly adhesive, } \\
\text { non-continuous }\end{array}$ & $\begin{array}{c}\text { well adhesive, } \\
\text { continuous }\end{array}$ \\
\hline 1000 & 250 & $\begin{array}{c}\text { poorly adhesive, } \\
\text { non-continuous }\end{array}$ & $\begin{array}{c}\text { well adhesive, } \\
\text { continuous }\end{array}$ \\
\hline 1000 & 380 & $\begin{array}{c}\text { poorly adhesive, } \\
\text { porous }\end{array}$ & $\begin{array}{c}\text { well adhesive, } \\
\text { continuous, porous }\end{array}$ \\
\hline 440 & 250 & $\begin{array}{c}\text { irregular thicknesses } \\
\text { double scale, } \\
\text { irregular thicknesses }\end{array}$ & $\begin{array}{c}\text { poorly adhesive, } \\
\text { continuous }\end{array}$ \\
\hline 440 & poorly adhesive, \\
continuous
\end{tabular}

Table 4 The depth of the cracks, measured on cross sections (Fig. 9) of samples tested in corrosion fatigue at the stress ranges of $380 \mathrm{MPa}, 250 \mathrm{MPa}$ and $100 \mathrm{MPa}$ in a solution with an initial $\mathrm{Fe}^{2+}$ of $440 \mathrm{mg} \mathrm{L}^{-1}$ and $1000 \mathrm{mgL}^{-1}$.

\begin{tabular}{c|c|c|c|}
\multirow{2}{*}{$\begin{array}{c}\text { Initial } \\
\mathrm{pH}\end{array}$} & \multirow{2}{*}{$\begin{array}{c}\text { Stress range } \\
{[\mathrm{MPa}]}\end{array}$} & \multicolumn{2}{|c|}{$\begin{array}{c}\text { Depth of the cracks } \\
{[\mu \mathrm{m}]}\end{array}$} \\
\cline { 3 - 4 } & & compression & tension \\
\hline 6.2 & 380 & $104 \pm 48$ & $625 \pm 364$ \\
6.2 & 250 & - & $20 \pm 6$ \\
6.2 & 100 & - & - \\
5.7 & 380 & $26 \pm 14$ & $43 \pm 10$ \\
5.7 & 250 & - & -
\end{tabular}




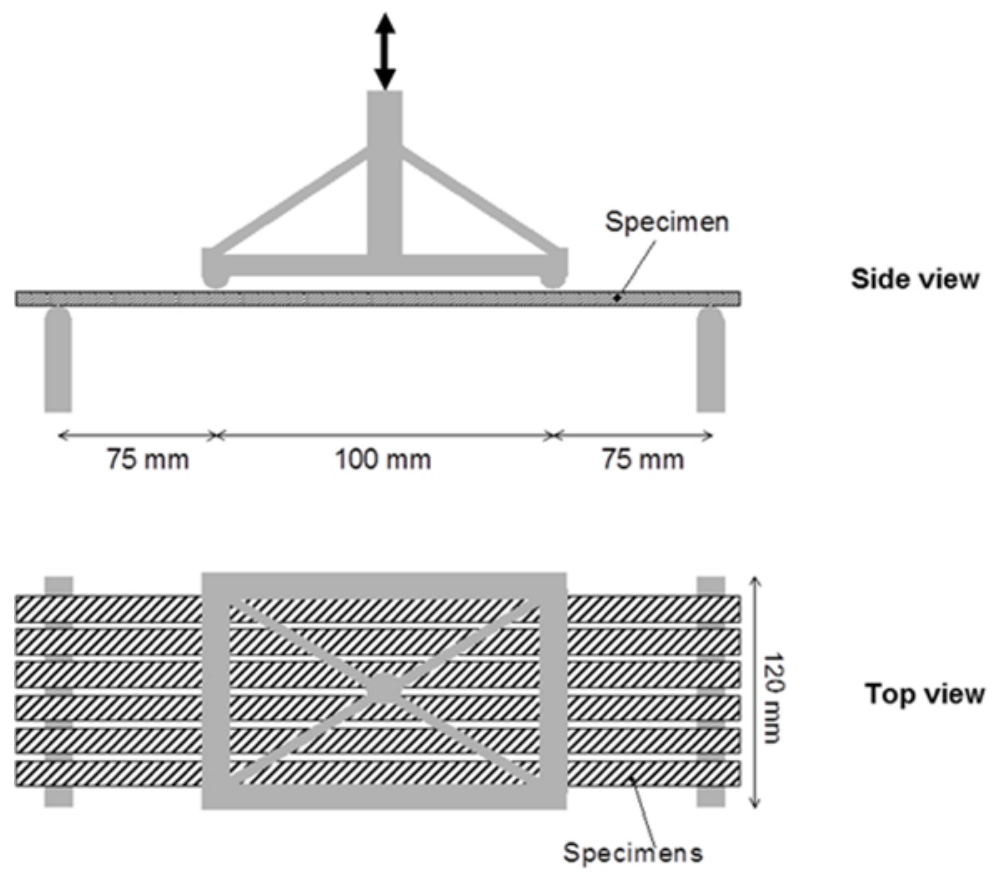

Fig. 1 Schematic illustration of a four point bending setup used for corrosion fatigue testing.

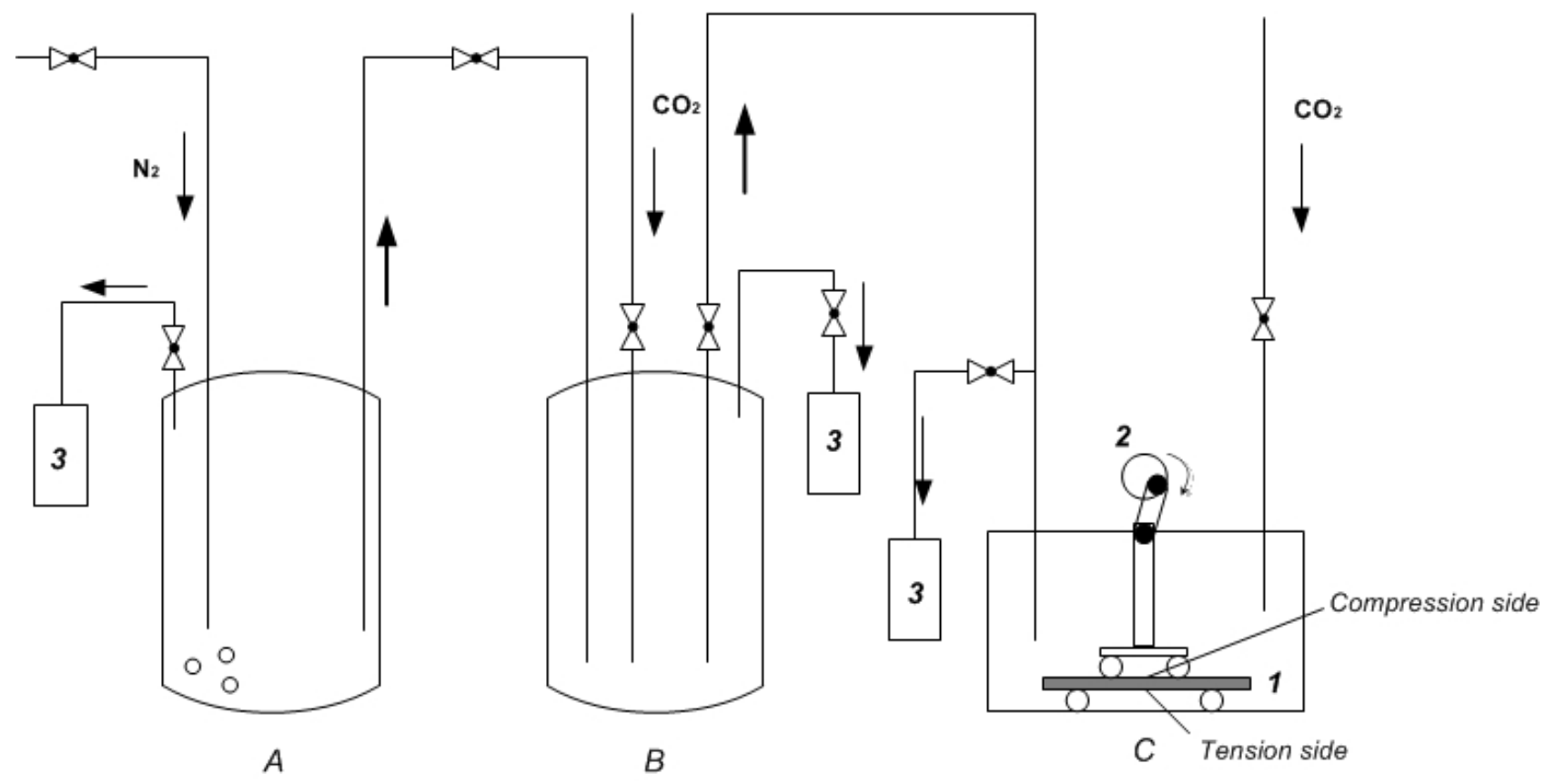

Fig. 2. Schematic drawing of the test set-up for corrosion fatigue testing: (A) De-aeration chamber, (B) Pre-corrosion chamber, (C) Test chamber ((1) Fatigue sample, (2) Eccentric, (3) Wash bottle). 


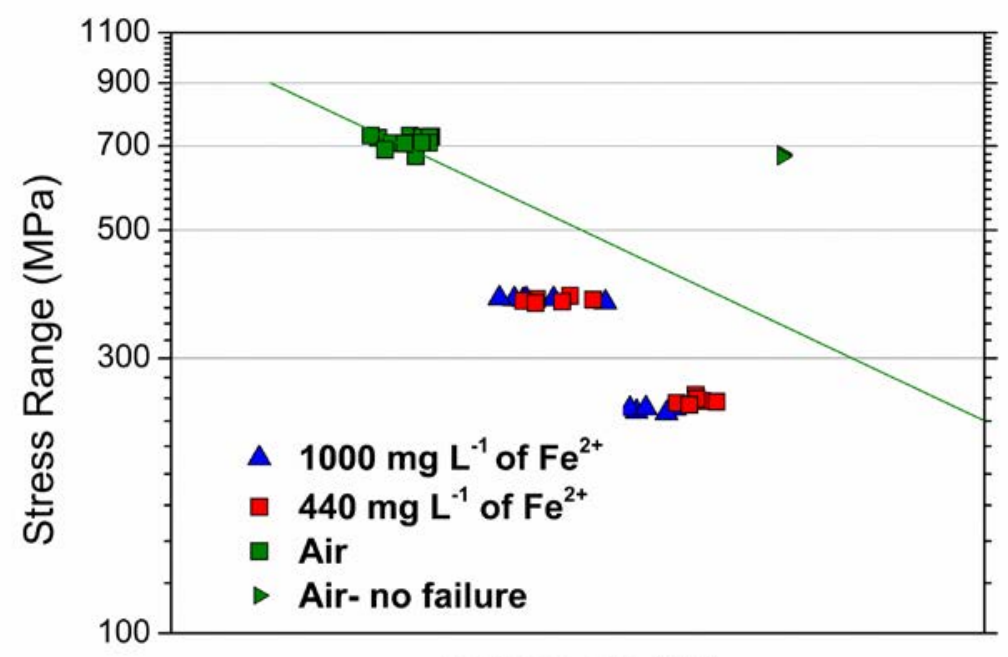

Fatigue life $\left(\mathrm{N}_{\mathrm{f}}\right)$

Fig. 3. Stress range as a function of fatigue life of samples exposed to air and seawater with 1 bar $\mathrm{CO}_{2}$ with initial $\mathrm{Fe}^{2+}$ concentration of $440 \mathrm{mg} \mathrm{L}^{-1}$ and $1000 \mathrm{mg} \mathrm{L}^{-1}$.
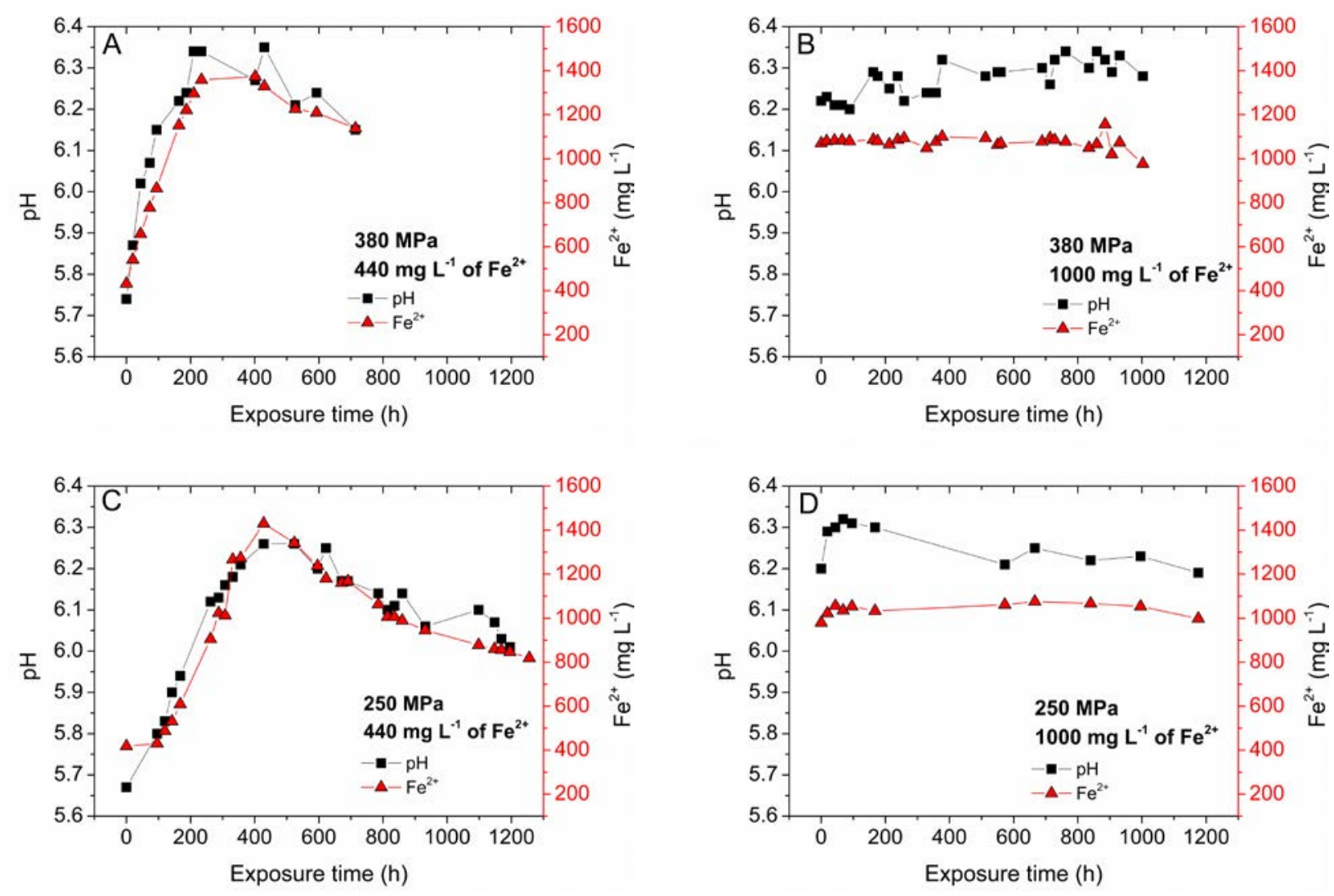


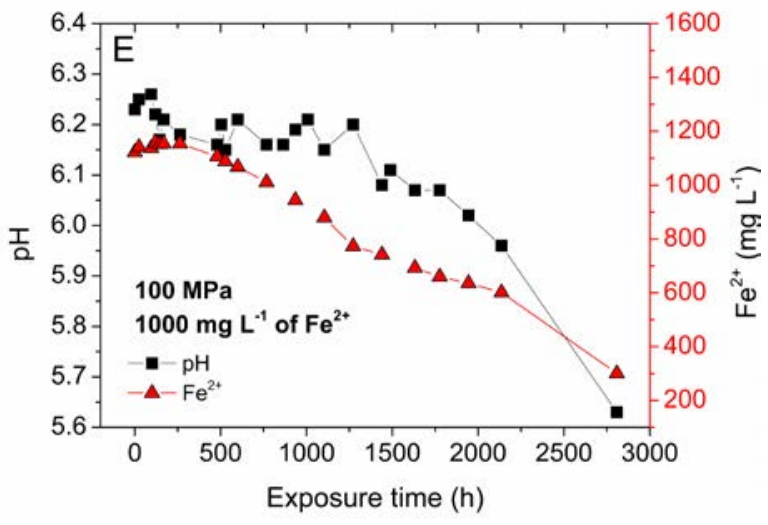

Fig. 4. The $\mathrm{pH}$ and $\mathrm{Fe}^{2+}$ development as a function of exposure time for corrosion fatigue tests performed at 1 bar $\mathrm{CO}_{2}$ and stress range of $380 \mathrm{MPa}(\mathrm{A}, \mathrm{B}), 250 \mathrm{MPa}(\mathrm{C}, \mathrm{D})$ and $100 \mathrm{MPa}(\mathrm{E})$ with solutions with an initial $\mathrm{Fe}^{2+}$ of $440 \mathrm{mg} \mathrm{L}^{-1}(\mathrm{~A}, \mathrm{C})$ and 1000 $\mathrm{mg} \mathrm{L}^{-1}(B, \mathrm{D}, \mathrm{E})$.
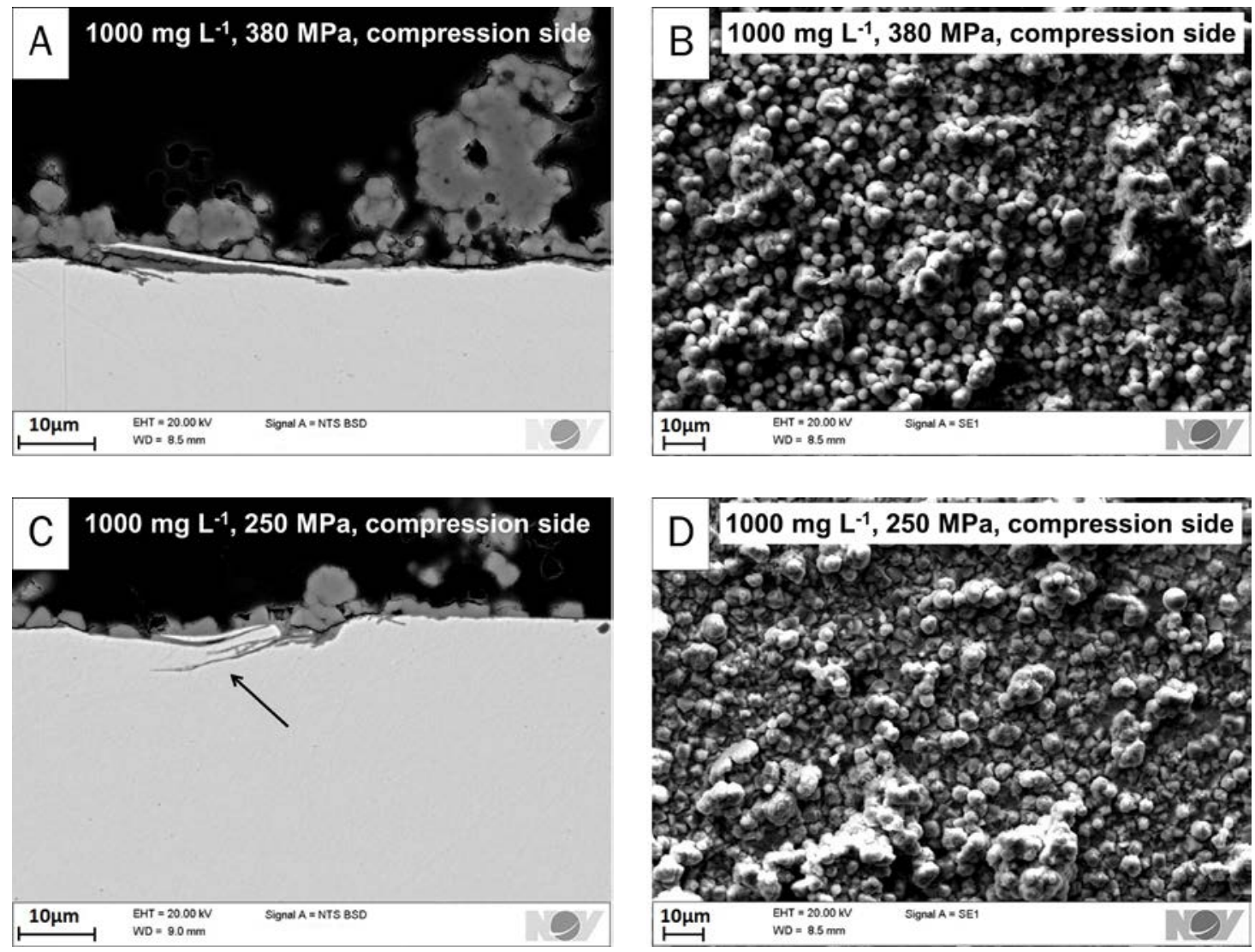

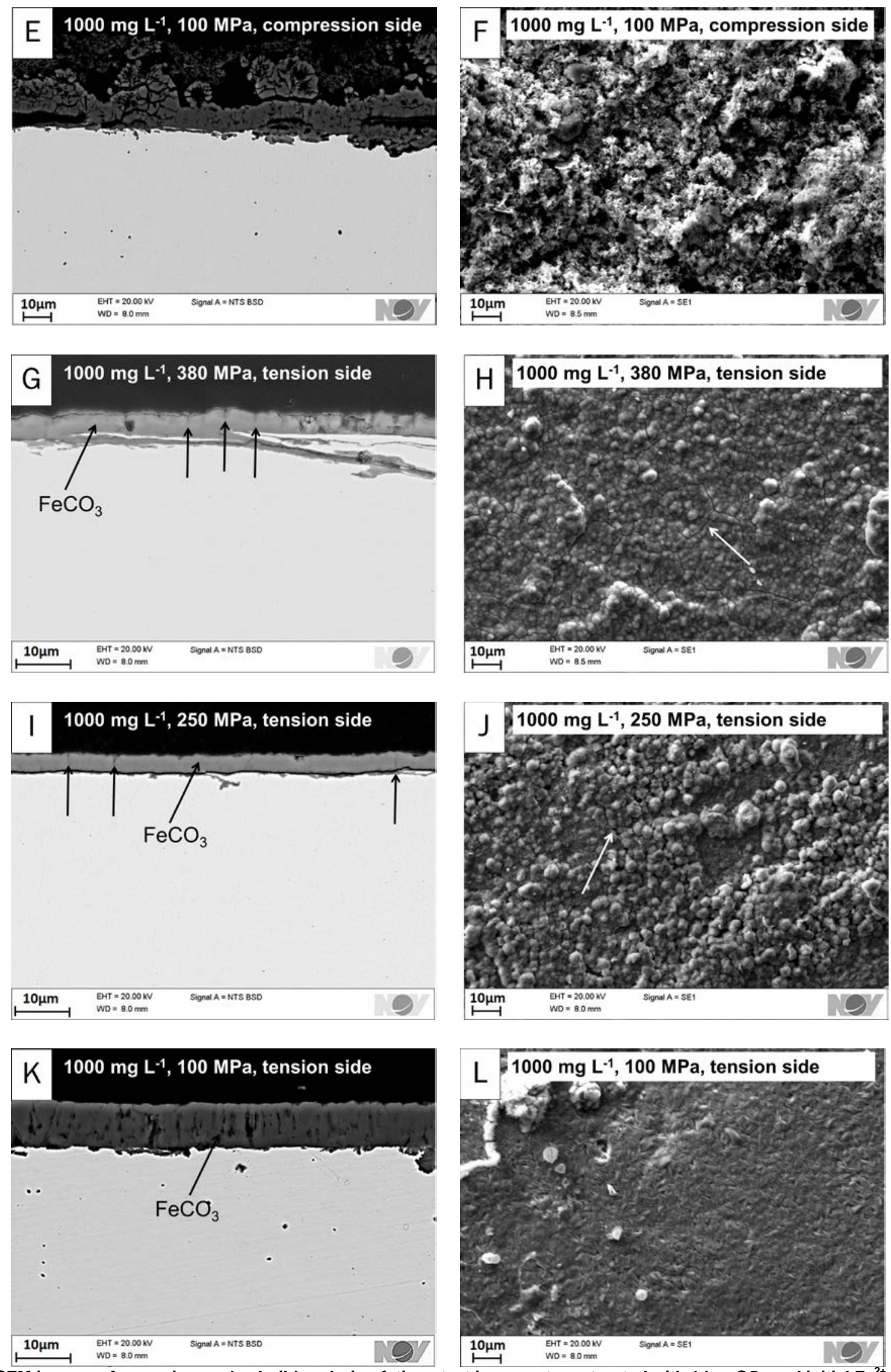

Fig. 5. SEM images of corrosion scales buildup during fatigue test in seawater saturated with 1 bar $\mathrm{CO}_{2}$ and initial $\mathrm{Fe}^{2+}$ of 1000 $\mathrm{mgL}^{-1}$. Images present corrosion scales developed on the compression and tension side at $380 \mathrm{MPa}, 250 \mathrm{MPa}$ and $100 \mathrm{MPa}$. 


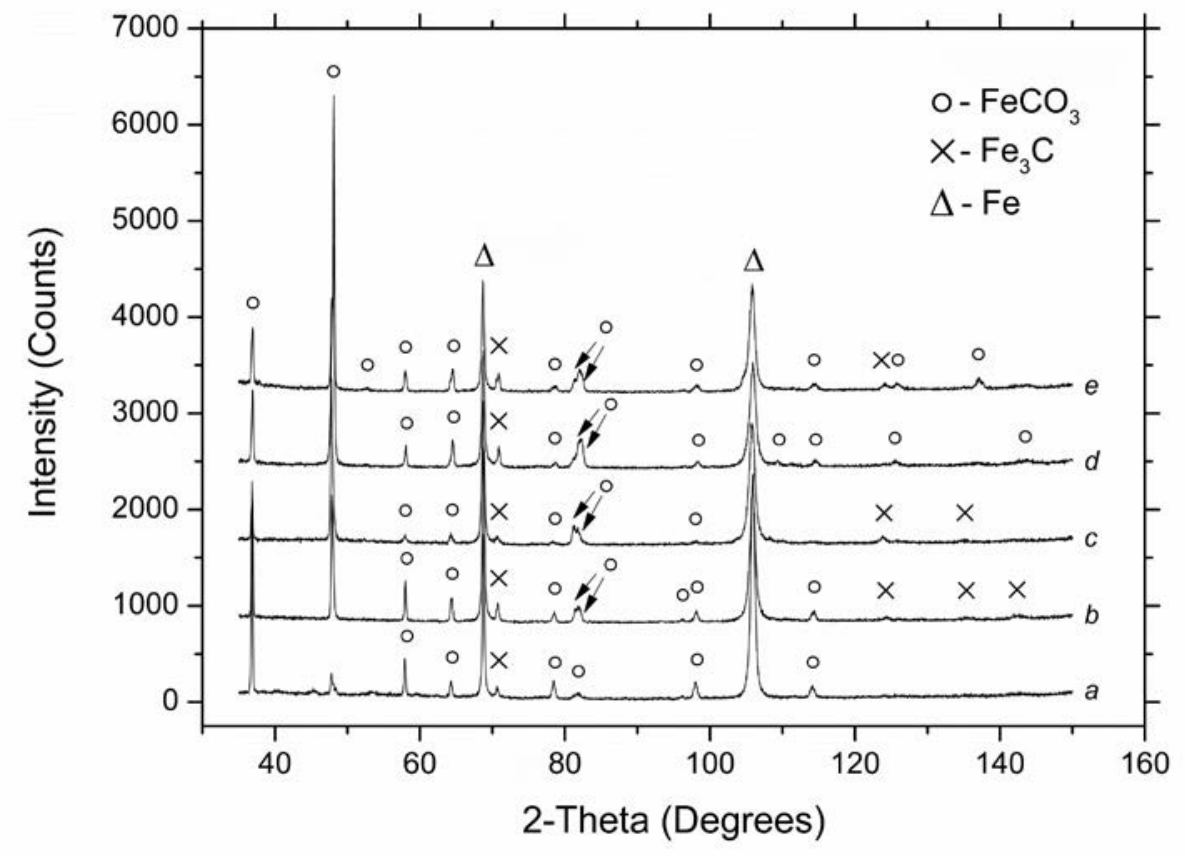

Fig. 6. XRD phase analysis for corrosion scales formed on the tension side of fatigue samples tested in solution with initial $\mathrm{Fe}^{2+}$ of $1000 \mathrm{mg} \mathrm{L}^{-1}$ at (a) $100 \mathrm{MPa}$, (b) $250 \mathrm{MPa}$, (c) $380 \mathrm{MPa}$; and Fe $\mathrm{Fe}^{2+} 440 \mathrm{mg} \mathrm{L}^{-1}$ at (d) $250 \mathrm{MPa}$ and (e) $380 \mathrm{MPa}$. Arrows mark two overlapping peaks representing $\mathrm{FeCO}_{3}$ phase.
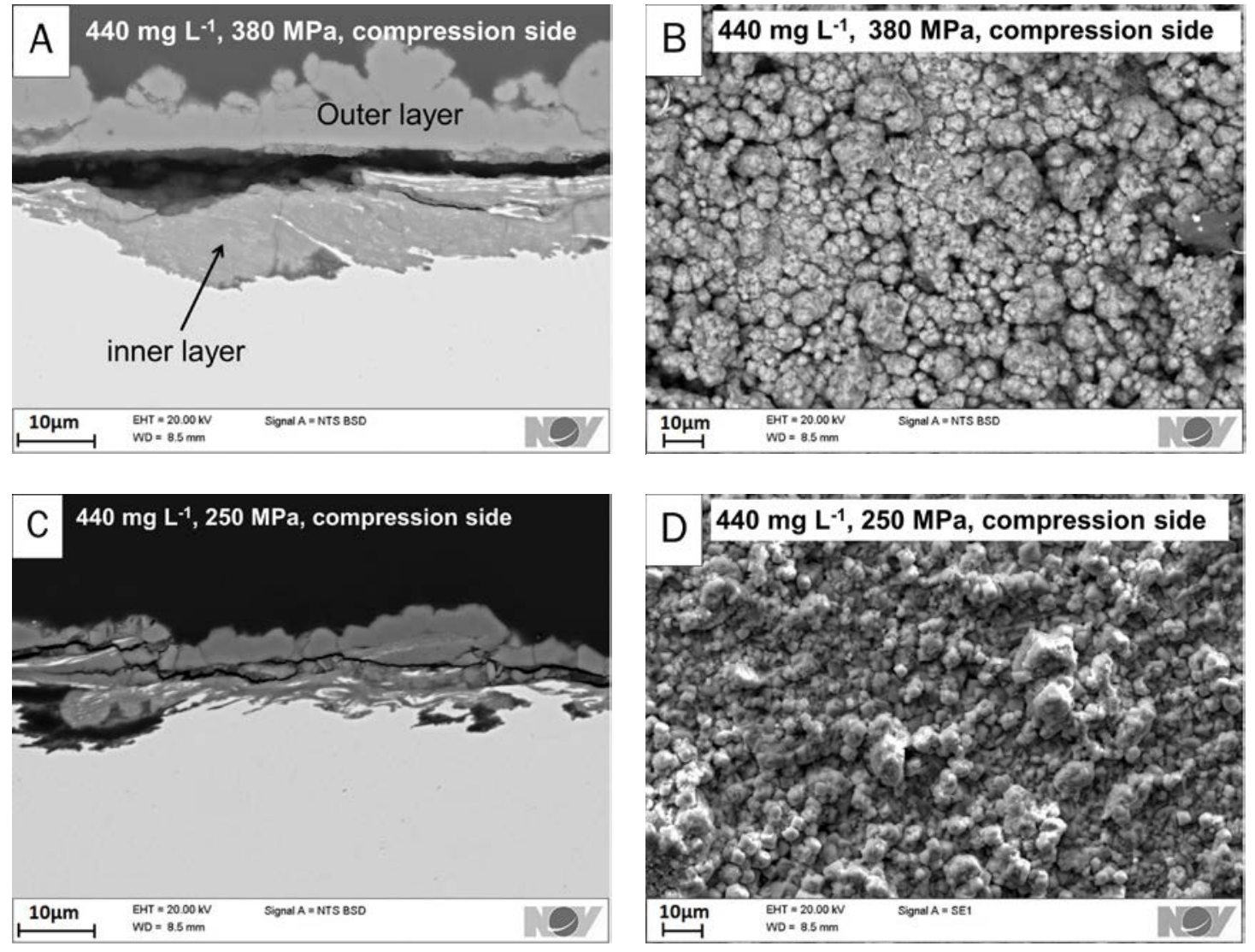

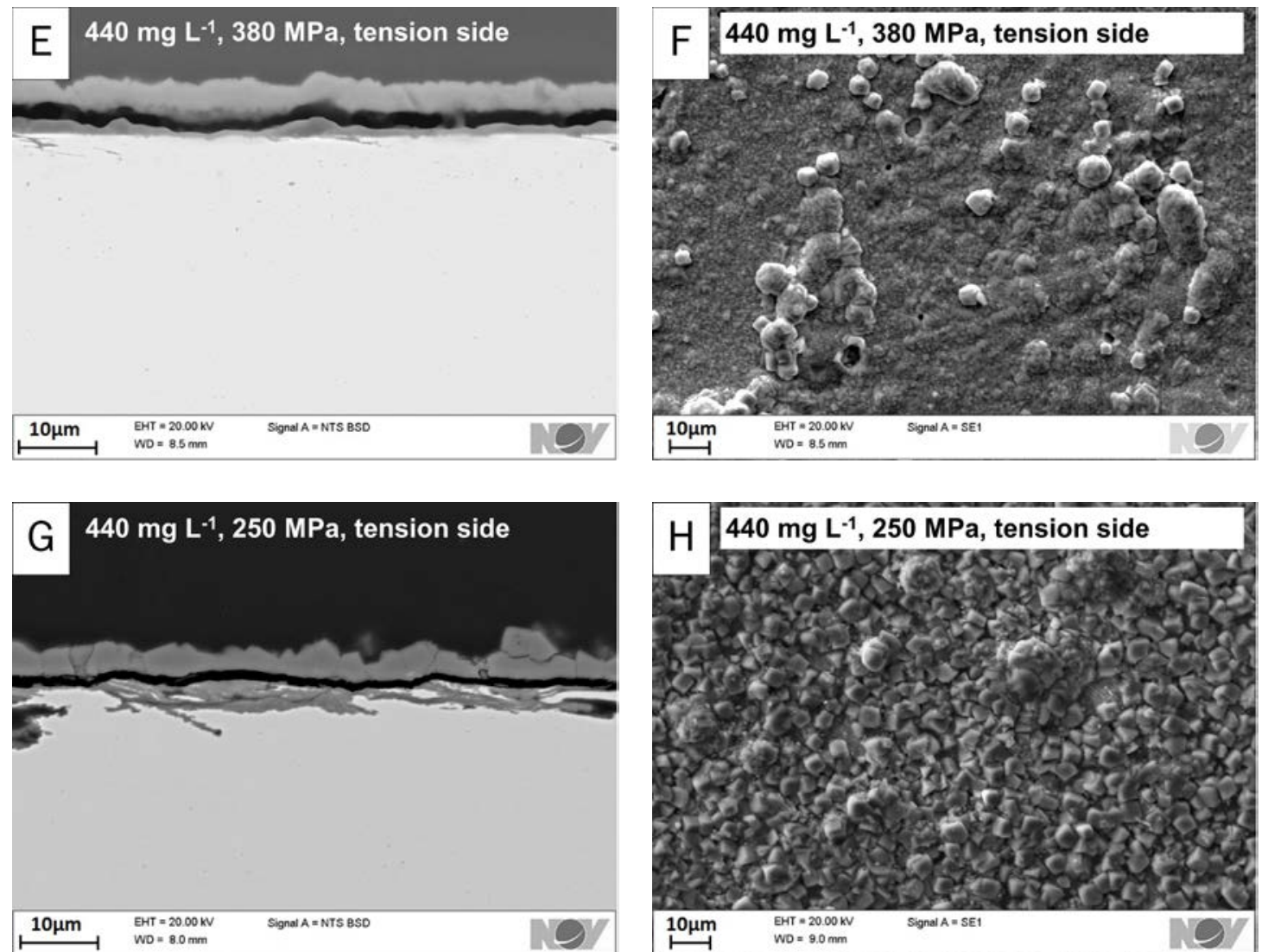

Fig. 7. SEM images of corrosion scales built during corrosion fatigue test in Seawater at $1 \mathrm{bar} \mathrm{CO}_{2}$ and initial $\mathrm{Fe}^{2+}$ of $440 \mathrm{mg} \mathrm{\textrm {L } ^ { - 1 }}$. Images present corrosion scales developed on the tension and compression sides for the stress ranges of $380 \mathrm{MPa}$ and 250 MPa.

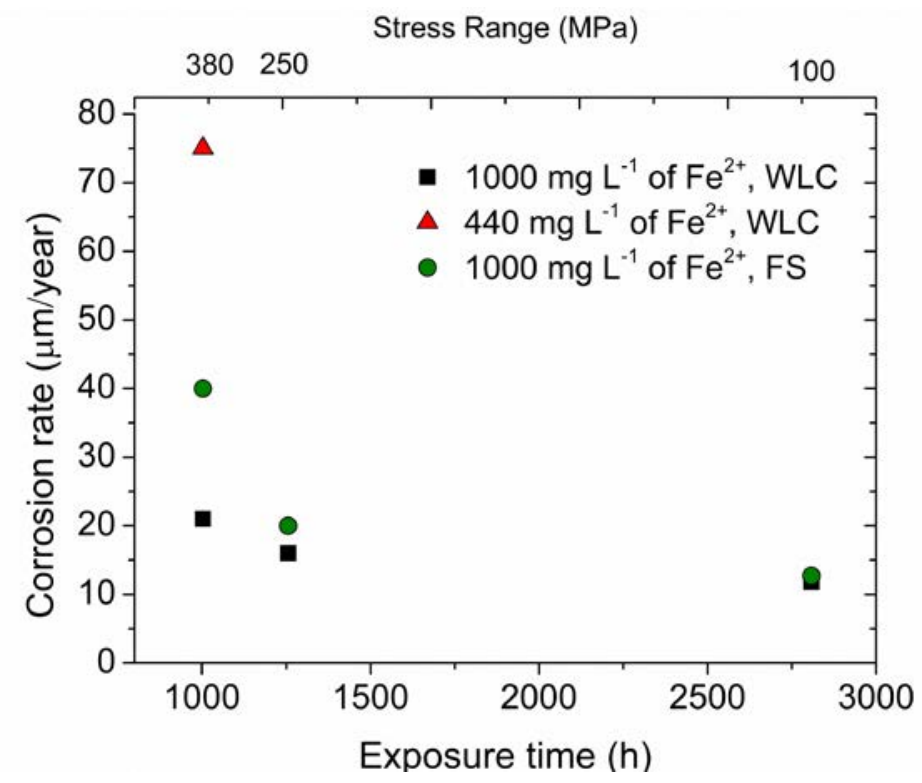

Fig. 8. Corrosion rates, based on weight loss coupons (WLC), which were not subjected to dynamic loading, and fatigue samples (FS) tested dynamically, for tests performed at stress ranges of $380 \mathrm{MPa}$ (1003 hours), $250 \mathrm{MPa}$ (1256 hours) and 100 $\mathrm{MPa}\left(2808\right.$ hours) in solutions with initial $\mathrm{Fe}^{2+}$ of $440 \mathrm{mg} \mathrm{L}^{-1}$ and $1000 \mathrm{mg} \mathrm{L}^{-1}$. 

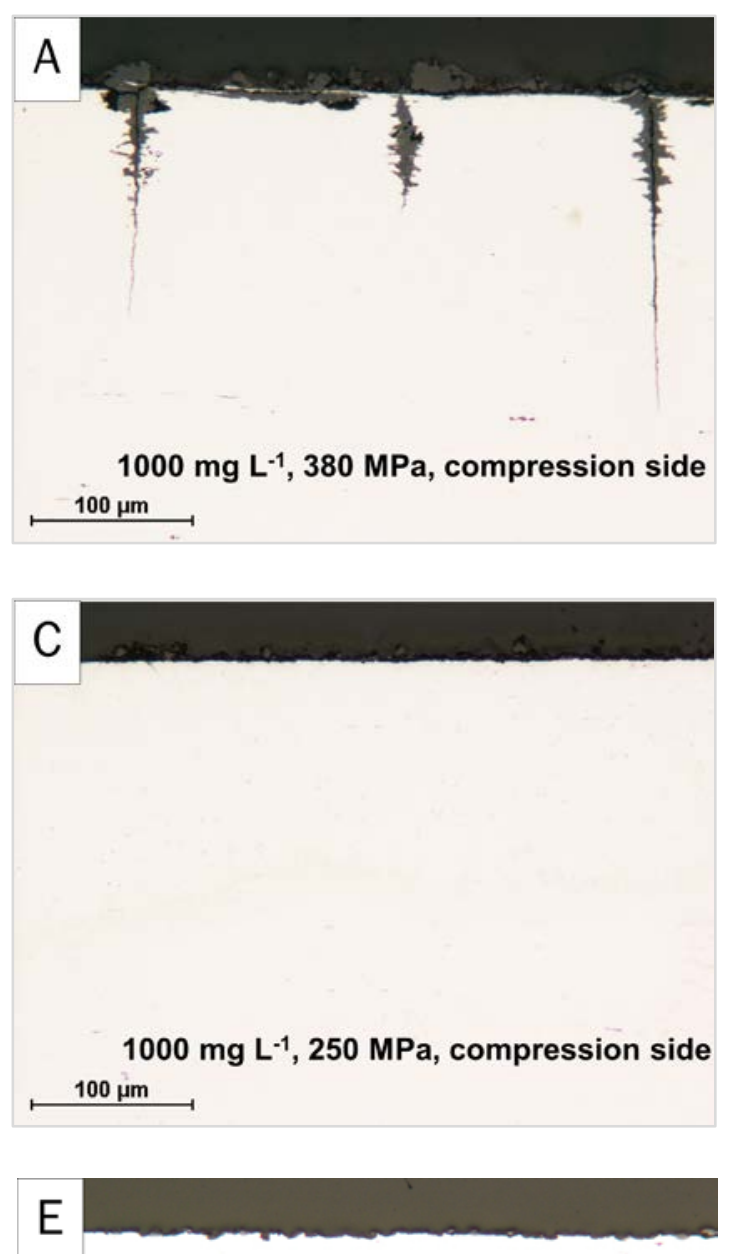

$1000 \mathrm{mg} \mathrm{L}^{-1}, 100 \mathrm{MPa}$, compression side $100 \mu \mathrm{m}$
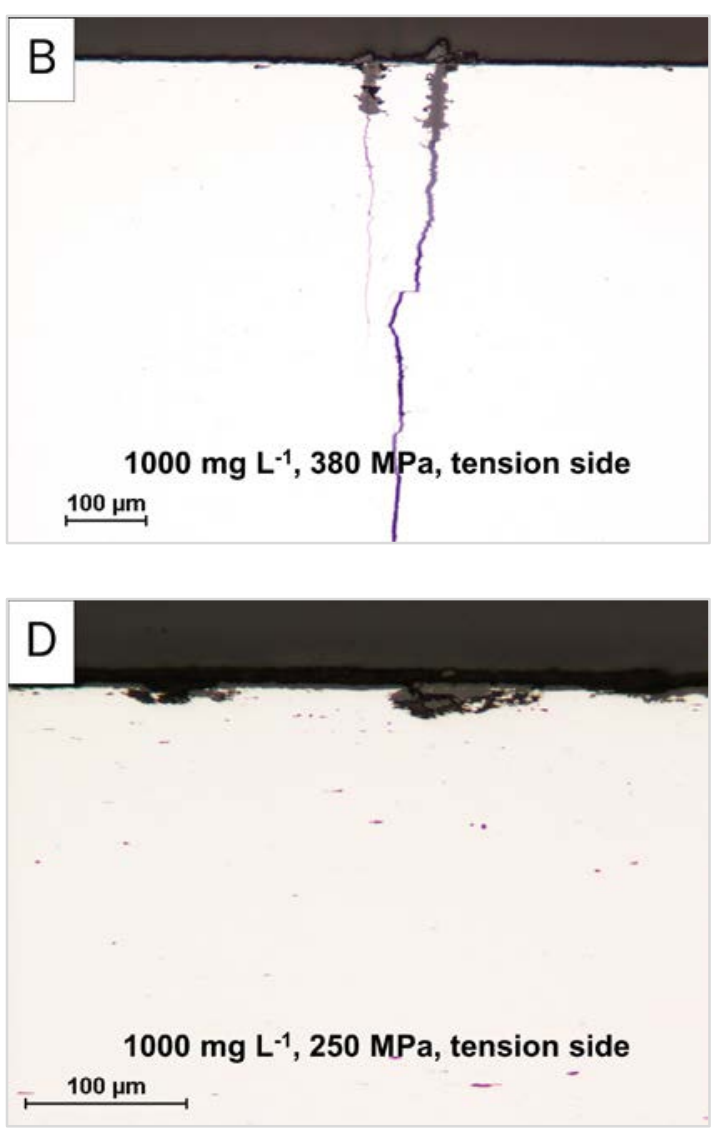

F

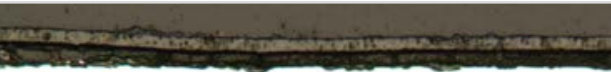

$1000 \mathrm{mg} \mathrm{L}^{-1}, 100 \mathrm{MPa}$, tension side $100 \mu \mathrm{m}$ 

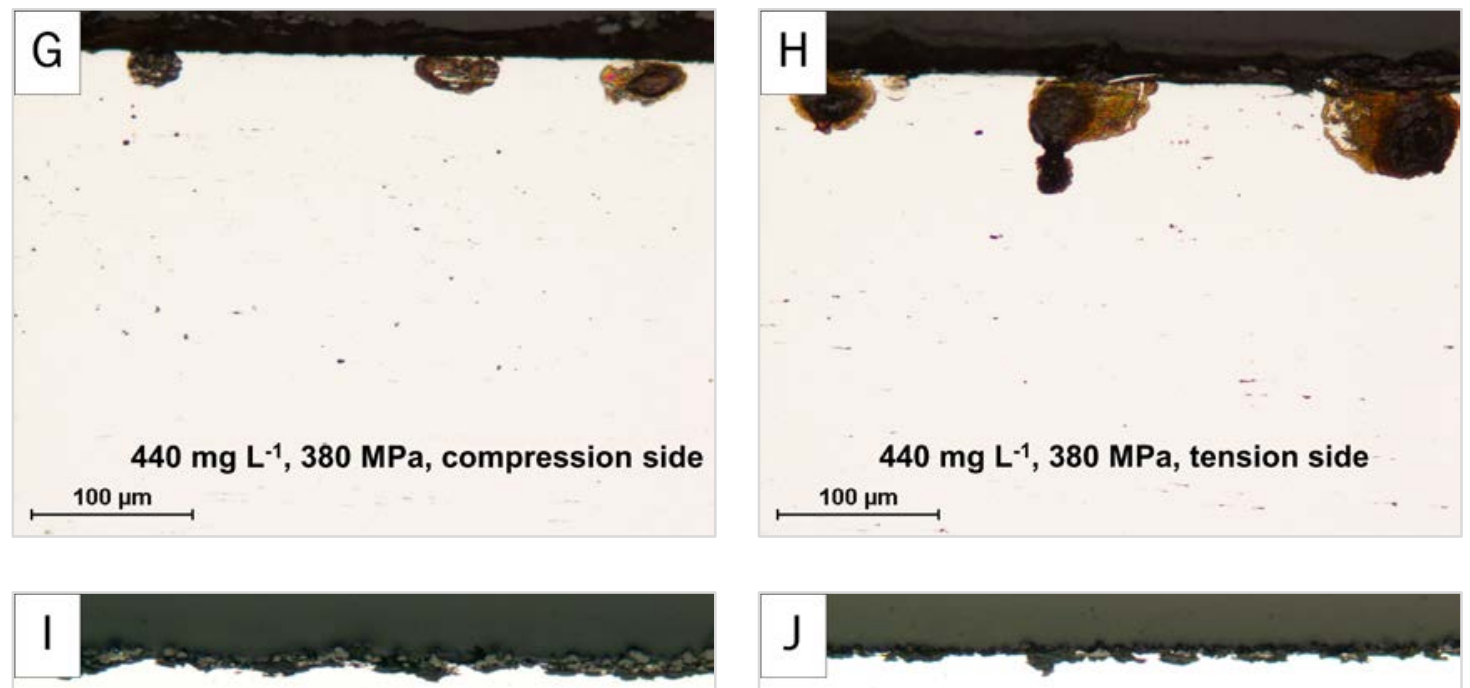

$440 \mathrm{mg} \mathrm{L}^{-1}, 250 \mathrm{MPa}$, compression side $100 \mu \mathrm{m}$

$440 \mathrm{mg} \mathrm{L}^{-1}, 250 \mathrm{MPa}$, tension side $100 \mu \mathrm{m}$

Fig. 9. LOM images of cracks formed for samples tested in corrosion fatigue at stress ranges of $380 \mathrm{MPa}, 250 \mathrm{MPa}$ and 100 $\mathrm{MPa}$ in solutions with an initial $\mathrm{Fe}^{2+}$ of $440 \mathrm{mg} \mathrm{L}^{-1}$ and $1000 \mathrm{mg} \mathrm{L}^{-1}$. 